\title{
HIV Protease Inhibitors Alter Amyloid Precursor Protein Processing via $\beta$-Site Amyloid Precursor Protein Cleaving Enzyme-1 Translational Up-Regulation
}

Patrick J. Gannon, ${ }^{* \dagger}$ Cagla Akay-Espinoza, ${ }^{\dagger}$ Alan C. Yee, ${ }^{\dagger}$ Lisa A. Briand,${ }^{\dagger}$ Michelle A. Erickson, ${ }^{\dagger}$ Benjamin B. Gelman,,${ }^{\S}$ Yan Gao, Norman J. Haughey, ${ }^{\|}$M. Christine Zink, ${ }^{* *}$ Janice E. Clements, ${ }^{* *}$ Nicholas S. Kim, ${ }^{\dagger}$ Gabriel Van De Walle, ${ }^{\dagger}$ Brigid K. Jensen,

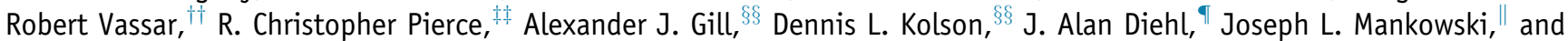
Kelly L. Jordan-Sciutto ${ }^{\dagger}$

From the Departments of Pharmacology, ${ }^{*}$ Psychiatry ${ }^{\ddagger \ddagger}$ and Neurology, ${ }^{\S}$ The Perelman School of Medicine, and the Department of Pathology, ${ }^{\dagger}$ School of Dental Medicine, University of Pennsylvania, Philadelphia, Pennsylvania; the Department of Psychology, ${ }^{\ddagger}$ Temple University, Philadelphia, Pennsylvania; the Department of Pathology, ${ }^{\S}$ University of Texas Medical Branch, Galveston, Texas; the Department of Biochemistry and Molecular Biology, ${ }^{\circledR}$ Hollings Cancer Center, Medical University of South Carolina, Charleston, South Carolina; the Richard T. Johnson Division of Neuroimmunology and Neurological Infections," Department of Neurology, and the Department of Molecular and Comparative Pathobiology, ** Johns Hopkins University School of Medicine, Baltimore, Maryland; and the Department of Cell and Molecular Biology, ${ }^{\dagger \dagger}$ Feinberg School of Medicine, Northwestern University, Chicago, Illinois

\author{
Accepted for publication \\ September 12, 2016. \\ Address correspondence to \\ Kelly L. Jordan-Sciutto, Ph.D. \\ Department of Pathology, \\ School of Dental Medicine, \\ University of Pennsylvania, \\ 240 S 40th St, Levy Bldg, \\ Room 312, Philadelphia, PA \\ 19104-6030. E-mail: jordank@ \\ upenn.edu.
}

\begin{abstract}
Mounting evidence implicates antiretroviral (ARV) drugs as potential contributors to the persistence and evolution of clinical and pathological presentation of HIV-associated neurocognitive disorders in the post-ARV era. Based on their ability to induce endoplasmic reticulum (ER) stress in various cell types, we hypothesized that ARV-mediated ER stress in the central nervous system resulted in chronic dysregulation of the unfolded protein response and altered amyloid precursor protein (APP) processing. We used in vitro and in vivo models to show that HIV protease inhibitor (PI) class ARVs induced neuronal damage and ER stress, leading to PKR-like ER kinase-dependent phosphorylation of the eukaryotic translation initiation factor $2 \alpha$ and enhanced translation of $\beta$-site APP cleaving enzyme-1 (BACE1). In addition, PIs induced $\beta$-amyloid production, indicative of increased BACE1mediated APP processing, in rodent neuroglial cultures and human APP-expressing Chinese hamster ovary cells. Inhibition of BACE1 activity protected against neuronal damage. Finally, ARVs administered to mice and SIV-infected macaques resulted in neuronal damage and BACE1 upregulation in the central nervous system. These findings implicate a subset of PIs as potential mediators of neurodegeneration in HIV-associated neurocognitive disorders. (Am J Pathol 2017, 187: 91-109; http://dx.doi.org/10.1016/j.ajpath.2016.09.006)
\end{abstract}

The prevalence of HIV-associated neurocognitive disorders (HAND), a spectrum of HIV-related central nervous system (CNS) dysfunctions ranging from mild cognitive deficits to HIV-associated dementia, remains high despite the success of antiretroviral (ARV) therapy in controlling HIV. ${ }^{1-4}$ Several groups reported immunoreactivity to amyloid precursor protein (APP) and its intracellular and extracellular proteolytic products in the frontal cortex and hippocampus of ARV-medicated subjects, whereas others observed accumulation only of hyperphosphorylated tau. ${ }^{5-11}$ Although increased longevity of HIV-infected patients is
This study used services offered by core facilities of the Comprehensive NeuroAIDS Center (National Institute of Mental Health grant P30MH092177) at Temple University School of Medicine. Supported by NIH grants: R01NS056885, R01MH083517, R01NS41202, R01MH098742 (K.L.J.-S.), MH077542, T32ES01985 (M.A.E.), MH096636, and MH075673 (N.J.H.), MH102120 (A.J.G.), MH095671, MH104134, NS043994, and NS27405 (D.L.K.), DA22339 and DA18678 (R.C.P.), MH070306 (J.E.C.), P01 CA104838 (J.A.D.), T32GM008076 (P.J.G.), and T32NS007180-29 and T32NS007180 (B.K.J.).

The following reagents were obtained through the AIDS Reagent Program, Division of AIDS, National Institue of Allergy and Infectious Diseases, NIH: ritonavir and saquinavir.

Disclosures: None declared. 
suggested to contribute to these changes in HAND neuropathology, other risk factors, such as peripheral toxicities of ARVs and potential central effects linked to enhanced amyloidogenesis and aging, remain largely underexplored.

Among the six classes of ARVs currently prescribed, nucleoside reserve transcriptase inhibitors (NRTIs) and HIV protease inhibitors (PIs) have the longest history of use and continue to be prescribed globally. NRTIs inhibit the viral reverse transcriptase enzyme, ${ }^{12}$ and PIs prevent gag-pol precursor polyprotein cleavage to block viral maturation. ${ }^{13}$ As a result of combination ARV therapy that incorporates several drugs from different categories with PIs, HIV-infected individuals have experienced a 50\% reduction in mortality rates with reduced HIV-associated dementia incidence. ${ }^{13}$ Despite their numerous benefits, ARVs were also linked to wide-ranging, peripheral metabolic and neural disturbances that could themselves influence HAND progression, including NRTI-associated mitochondrial dysfunction manifesting as peripheral neuropathy and myopathy ${ }^{14,15}$ and PI-associated dyslipidemia, hypercholesterolemia, and metabolic syndrome. ${ }^{16-22}$

We previously demonstrated that ARV administration lead to synaptodendritic damage in healthy adult rats and SIV-infected macaques. ${ }^{23}$ We and others also showed ARVmediated accumulation of reactive oxygen species and eventual synaptic damage and neuronal death in cortical neurons. $^{23,24}$ These data support a growing body of evidence for significant ARV-associated CNS neurotoxic effects, as was shown in the peripheral nervous system, and suggest that ARVs may affect long-term neurocognitive outcomes in patients. More importantly, both NRTIs and PIs were shown to induce numerous cellular stress response pathways, including endoplasmic reticulum (ER) and oxidative stress, both of which were demonstrated in HAND and other neurodegenerative diseases, such as Alzheimer disease (AD) ${ }^{25,26}$ Diverse cellular stressors converge on a ubiquitous intracellular response mechanism termed the unfolded protein response (UPR; alias ER stress response) ${ }^{27,28}$ In eukaryotes, misfolded protein accumulation and/or other stressors disrupt the interaction between the ER-resident chaperone, binding protein (BiP), and the luminal domain of one or more of the three ER membranebound UPR sensors, PKR-like ER kinase (PERK), activating transcription factor 6 (ATF6), and inositol-requiring enzyme $1 \alpha$, in the ER, permitting their consequent activation $^{29}$; however, UPR activation is promiscuous as it can be activated in response to a wide range of stimuli. Downstream effects of UPR induction include global protein synthesis attenuation via eukaryotic translation initiation factor $2 \alpha$ (eIF2 $\alpha$ ) phosphorylation, up-regulation of genes containing the ER stress response element, and ERmediated protein degradation. ${ }^{30}$

Although transient UPR activation serves a protective function, the chronic nature of cellular stress and stress response activation in the CNS during HIV infection may ultimately overwhelm ER's buffering capacity, resulting in aberrant UPR activation and eventual cell death. ${ }^{26,31} \mathrm{We}$ and others demonstrated a potential role for ER stress and UPR activation in HAND pathogenesis, as well as in other neurodegenerative diseases. ${ }^{22,26,32,33}$ In postmortem brain tissue from $\mathrm{ARV}$-treated, $\mathrm{HIV}^{+}$patients and $\mathrm{AD}$ patients, expression levels of BiP, phosphorylated eIF $2 \alpha$ (p-eIF2 $\alpha$ ), ATF6 $\beta$, and other UPR markers were increased, primarily in neurons. ${ }^{26,30,34}$ Interestingly, Vassar and colleagues ${ }^{35,36}$ showed that in vivo UPR activation via glucose deprivation or tunicamycin in the CNS resulted in increased APP and $\beta$-amyloid $(\mathrm{A} \beta)$ deposition $^{35-37}$ and that impaired brain energy metabolism lead to chronic PERK activation, sustained eIF2 $\alpha$ phosphorylation, and $\beta$-site APP cleaving enzyme 1 (BACE1) up-regulation. ${ }^{36}$ Phosphorylation of eIF2 $\alpha$ inhibits global protein translation while up-regulating the translation of a subset of mRNA species that contain multiple upstream open reading frames in their $5^{\prime}$ untranslated regions (5' UTRs), including BACE1 ${ }^{36}$ BACE1, an aspartyl protease critical for the generation of $A \beta$ from APP, was up-regulated in the CNS of AD patients. ${ }^{38,39}$ Increased BACE1 expression and activity were correlated with plaque number and cognition status, and BACE1 was implicated as a biomarker for mild cognitive impairment and $\mathrm{AD} .{ }^{39}$ Altogether, these studies suggest that UPR-mediated up-regulation of BACE1 may function as an early event in $\mathrm{AD}$ pathogenesis.

In the present study, we determined the mechanisms by which ARVs induced damage and death in primary neuroglial cultures and in vivo models. We also assessed whether altered BACE1 expression and function were contributors. We showed that two PIs, ritonavir and saquinavir, which were previously shown to induce oxidative stress and synaptic loss, ${ }^{23,24}$ induced neuronal damage and ER stress in neuroglial cultures, leading to UPR activation and PERKdependent translational BACE1 up-regulation. In addition, we found that PIs enhanced the production of $A \beta$ peptides in neurons and human APP-expressing Chinese hamster ovary (CHO) cells. Moreover, these findings were corroborated with increased expression of BACE1 in macaques and rodents that received chronic ARV treatment in vivo. These studies suggested that PIs might alter APP processing and contribute to the changing neuropathology and persistence of cognitive decline among $\mathrm{ARV}$-treated, $\mathrm{HIV}^{+}$individuals.

\section{Materials and Methods}

\section{Chemicals and Reagents}

The following antibodies used in this study were purchased from the indicated vendors or provided by the indicated colleagues: Abcam (Cambridge, MA): synaptophysin (ab8049), a disintegrin and metalloprotease 10 (ADAM10) (ab1997), and microtubule-associated protein (MAP2) (5392); BD Biosciences (San Jose, CA): BiP (610978); Cell Signaling Technology (Danvers, MA): BACE1 (5606S), phospho-eIF2 $\alpha$ (9721), total eIF2 $\alpha$ (9722), lamin A/C (2032), and presinilin-1 (5643); Covance (Princeton, NJ): 
APP (6E10); Santa Cruz Biotechnology (Dallas, TX): glyceraldehyde-3-phosphate dehydrogenase (sc-32233) and actin (A2066). The mouse monoclonal antibody against BACE1 (3d5) was a generous gift from Dr. Robert Vassar (Feinberg School of Medicine, Northwestern University, Chicago, IL). The antibody against activating transcription factor 4 (ATF4) was generously provided by Dr. Ron Wek (School of Medicine, Indiana University, Indianapolis). The rabbit monoclonal antibody against PERK was a generous gift from J.A.D. The following chemical reagents used in the study were purchased from the indicated vendors: Citifluor, Ltd (London, UK): citifluor AF1; BioRad (Hercules, CA): bradford protein assay dye, polyvinylidene difluoride membrane, and prestained broad-range molecular weight ladder; Jackson ImmunoResearch Labs (West Grove, PA): all dye-conjugated secondary antibodies; Life Technologies (Carlsbad, CA): Dulbecco's modified Eagle's medium, neurobasal media, and B27 supplement; Millipore (Temecula, CA): $20 \mathrm{~S}$ proteasome activity assay; Nanotherics (Newcastle under Lyme, UK): neuromag transfection reagent; Sigma (St. Louis, MO): DAPI, fast green FCF, protease inhibitor cocktail, 4-hydroxytamoxifen (H7904), anisomycin (A9789), and actinomycin D (A1410); Peptides International (Louisville, KY): poly-L-lysine; New England Biolabs (Ipswich, MA): tyramide amplification system; Scytek Labs (Logan, UT): normal antibody diluent; Thermo Fisher Scientific (Waltham, MA): SuperSignal West Dura extended-duration substrate and all horseradish peroxidase-conjugated secondary antibodies. Antiretroviral reagents were kindly provided by the AIDS Research and Reference Reagent Program, Division of AIDS, National Institute of Allergy and Infectious Diseases, NIH (Bethesda, MD).

\section{Ethics Statement}

All pigtailed macaques (Macaca nemestrina) were housed and cared for in an indoor ABSL2 facility at the fully Association for Assessment and Accreditation of Laboratory Animal Care International-accredited Johns Hopkins University Research Animal Resources facility in accordance with standards of the Animal Welfare Regulations, the eighth edition of the Guide for the Care and Use of Laboratory Animals, ${ }^{40}$ and the Weatherall Report. All animal studies were approved by the Johns Hopkins University Institutional Animal Care and Use Committee (approval number PR12M310). Animal welfare was optimized through social housing and provision of both edible and manipulanda environmental enrichment by a dedicated behaviorist. Water was supplied ad libitum, and animals were provided commercial monkey chow twice daily and fresh produce at least three times per week. Animals were monitored daily by animal care and veterinary staff and sedated with ketamine anesthesia for all sampling by skilled veterinary personnel. Euthanasia was performed under deep pentobarbital anesthesia by skilled veterinary personnel, and tissues were perfused to decrease contamination by blood and peripheral virus. The negative control animals were mock-inoculated, and samples were obtained at the same time points as for the inoculated, untreated macaques.

\section{SIV/Pigtail Macaque Model of Lentiviral CNS Disease}

Pigtailed macaques (M. nemestrina) were inoculated with SIV/DeltaB670 and SIV/17E-Fr, as described previously. ${ }^{41}$ Twelve days after infection, animals were divided into placebo and ARV-treated groups until necropsy (range, day 161 to 175). ARV treatment was composed of the NRTI tenofovir (Gilead, Oceanside, CA) at $30 \mathrm{mg} / \mathrm{kg}$ s.c. given once daily, saquinavir (Roche, Basel, Switzerland) and atazanavir (Bristol-Myers Squibb, New York, NY) at 205 and $270 \mathrm{mg} / \mathrm{kg}$, respectively, given twice daily via oral administration, and an integrase inhibitor, L-870812 (Merck, Kenilworth, NJ), ${ }^{42}$ at $10 \mathrm{mg} / \mathrm{kg}$ orally twice daily. ${ }^{43}$ Tenofovir dosing was based on previous studies, ${ }^{44}$ whereas saquinavir and atazanavir dosing was based on pharmacokinetic analysis performed in pigtail macaques to reflect the area under the curve parameters similar to those detected in humans treated with atazanavir and saquinavir. ${ }^{43}$ L-870812 dosing was based on previous studies conducted in rhesus macaques. ${ }^{42}$

\section{Rodent Model of ARV-Induced Neurotoxicity}

All surgical procedures were performed with the approval of the Institutional Animal Care and Use Committee of the University of Pennsylvania (Philadelphia; approval number 803156). Adult male C57BL/6 mice were catheterized via the jugular vein, as described previously. ${ }^{45}$ Before surgery, mice were anesthetized with $80 \mathrm{mg} / \mathrm{kg}$ ketamine and $12 \mathrm{mg} / \mathrm{kg}$ xylazine. An indwelling silastic catheter was placed into the right jugular vein, sutured in place, and connected to a backmount platform (Strategic Applications, Inc., Lake Villa, IL) that was s.c. secured on the back of the animals with sutures. Catheters were flushed daily with $0.1 \mathrm{~mL}$ of the antibiotic clavulanic acid and ticarcillin (Timentin; bioWORLD, Dublin, OH) dissolved in heparinized saline (0.93 $\mathrm{mg} / \mathrm{mL}$ ). Treatment regimens were as follows: vehicle [dimethyl sulfoxide (DMSO)], ritonavir $(20 \mathrm{mg} / \mathrm{kg}$ ), or saquinavir $(25 \mathrm{mg} / \mathrm{kg})$, administered twice daily for 14 days by continuous i.v. injection. These drug doses were based on previously published pharmacokinetic studies in rodents. ${ }^{46-48}$ At the time of euthanasia, catheter patency was reverified by response to pre-euthanasia sedation $(80 \mathrm{mg} / \mathrm{kg}$ ketamine and $12 \mathrm{mg} / \mathrm{kg}$ xylazine). Euthanasia was performed by carbon dioxide administration, followed by cervical dislocation and decapitation to confirm death. Brains were removed, frontal cortex and hippocampus were dissected on ice, and tissue samples were stored at $-80^{\circ} \mathrm{C}$ until immunoblot analyses were performed (vehicle, $n=6$; ritonavir, $n=7$; saquinavir, $n=7$ ). 


\section{Preparation of Primary Neuroglial Cultures}

Primary rat or mouse cortical neuroglial cultures were isolated from brains of embryonic day 16 Sprague-Dawley rat pups or embryonic day 16.5 to 17.5 floxed PERK (PERK $^{\text {loxP/loxP }}$ ) mice, with modifications of previously described protocols. ${ }^{49}$ Briefly, to generate neuroglial cultures, cortical cell suspensions were isolated from rat or mouse embryos and were plated on poly-L-lysine-coated tissue culture dishes. Cultures were maintained in neurobasal media supplemented with $\mathrm{B} 27$ at $37^{\circ} \mathrm{C}$ with $5 \% \mathrm{CO}_{2}$, as described previously. ${ }^{50}$ Unless otherwise indicated, all experiments were performed at 21 days in vitro (DIV) in cultures containing approximately $90 \%$ neurons and $10 \%$ astrocytes/glia at a density of 500,000 cells $/ \mathrm{mL}$. Pure neuronal cultures were prepared by treating neuroglial cultures with $10 \mu \mathrm{mol} / \mathrm{L}$ cytosine arabinoside 48 hours after plating and were maintained in neurobasal media with B27 at $37^{\circ} \mathrm{C}$ with $5 \% \mathrm{CO}_{2}$.

Human primary cortical neurons were obtained from the Comprehensive NeuroAIDS Center, Temple University (Philadelphia, PA). Cultures were prepared from fetal brain tissue (gestational age, 16 to 18 weeks) performed in full compliance with the NIH and Temple University ethical guidelines, as described previously. ${ }^{51} \mathrm{~A}$ total of $50 \%$ of the culture media was changed every 4 days, and cultures were maintained at $37^{\circ} \mathrm{C}$ with $5 \% \mathrm{CO}_{2}$ for $21 \mathrm{DIV}$.

Previously characterized $\mathrm{PERK}^{\mathrm{loxP} / \mathrm{loxP}}$ mice $^{52}$ were crossed with tamoxifen-inducible cre $\left(\mathrm{Cre}-\mathrm{ERT}_{2}\right)$ heterozygous mice, and the resulting PERK ${ }^{\text {loxP/loxP }} ;$ Cre-ERT $_{2}$ mice were kindly provided by Dr. Alan Diehl. PERK deletion was achieved by treating 10 DIV mouse neuroglial cultures with various concentrations of 4hydroxytamoxifen. Antiretroviral drug treatments were performed 4 days after 4-hydroxytamoxifen treatment to allow for maximal PERK excision. Sixteen hours after antiretroviral drug treatments, PERK $^{-1-}$ neuroglial cultures were harvested for immunoblotting and genotyping using routine methods.

\section{Drug Treatments}

Twenty-one DIV rat cortical neuroglial cultures or human fetal neurons were treated with indicated log-fold concentrations of zidovudine (AZT; $25 \mathrm{mmol} / \mathrm{L}$ stock in sterile water), or saquinavir or ritonavir (both drugs prepared in DMSO at $25 \mathrm{mmol} / \mathrm{L}$ stock concentrations). The final concentration of DMSO was $0.04 \%$ for all treatments. All antiretroviral drugs were added to neuroglial cultures 16 hours before harvest. Anisomycin and actinomycin D were prepared in DMSO at 50 and $5 \mathrm{mmol} / \mathrm{L}$ stock concentrations, respectively. Twenty-one DIV rat cortical neuroglial cultures were pretreated with either 10 or $50 \mu \mathrm{mol} / \mathrm{L}$ anisomycin or $5 \mu \mathrm{mol} / \mathrm{L}$ actinomycin $\mathrm{D}$ for 12 hours, followed by treatment with $10 \mu \mathrm{mol} / \mathrm{L}$ ritonavir for 16 hours.

\section{Immunoblotting}

Whole cell extracts of primary rat cortical cultures were prepared with ice-cold whole cell lysis buffer containing

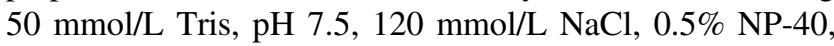
and $0.4 \mathrm{mmol} / \mathrm{L} \mathrm{Na}_{3} \mathrm{VO}_{4}$, supplemented with protease inhibitors. Lysates were centrifuged at $14,000 \times g$ at $4{ }^{\circ} \mathrm{C}$ for 10 minutes. Protein concentrations were determined using the Bradford method, and equal amounts of protein (15 to $20 \mu \mathrm{g}$ ) were loaded into each well of $4 \%$ to $12 \%$ Bis-Tris gradient gels or $3 \%$ to $8 \%$ Tris-acetate gradient gels (for confirmation of PERK overexpression). After transfer at $25 \mathrm{~V}$ at room temperature for 1 hour, polyvinylidene difluoride membranes were blocked in tris-buffered saline containing Tween 20 and 5\% bovine serum albumin for at least 30 minutes at room temperature. Membranes were then incubated in primary antibodies overnight at $4{ }^{\circ} \mathrm{C}$, washed with tris-buffered saline and Tween 20, and incubated with appropriate horseradish peroxidase-conjugated secondary antibodies for 30 minutes at room temperature. Membranes were developed using SuperSignal West Dura extended duration substrate, and densitometric analyses were performed using NIH ImageJ software program version 1.44 (NIH, Bethesda, MD). Equal loading and transfer were confirmed by fast green staining of membranes. Band densities of interest were normalized to the indicated loading controls or fast green-stained membranes. Immunoblots shown are representative of at least three independent biological replicates.

\section{RNA Isolation and Quantitative RT-PCR}

Total RNA was isolated from primary rat neuroglial cultures using the RNeasy Mini Kit (Qiagen, Valencia, CA). To assess the expression of spliced $X B P-1$ and $B A C E 1$ genes, $1 \mu \mathrm{g}$ total RNA from each sample was processed by SuperScript II First-Strand Synthesis system (Invitrogen, Carlsbad, CA). Approximately 100 ng cDNA was amplified via quantitative RT-PCR using Custom TaqMan Gene Expression Assays from Applied Biosystems (Foster City, CA). Relative expression of mRNA levels from samples was quantified using the comparative CT method, and data were normalized to unspliced $X B P-1$ and $T B P$ for spliced $X B P-1$ and $B A C E 1$ genes, respectively. All samples were run in triplicate, and experiments were repeated in at least three biological replicates.

\section{Human/Rat $A \beta$ ELISAs}

Cell media from 21 DIV primary rat neuroglial cultures and $\mathrm{CHO}$ cells stably expressing human wild-type APP were diluted 25-fold and assessed with a human/rat $\mathrm{A} \beta_{42^{-}}$or $\mathrm{A} \beta_{40^{-}}$ specific sandwich enzyme-linked immunosorbent assay (ELISA) (Wako Chemicals, Richmond, VA), according to the manufacturer's protocols. For experiments including $\mathrm{CHO}$ cells, cultures were pretreated with $10 \mathrm{nmol} / \mathrm{L}$, 
$100 \mathrm{nmol} / \mathrm{L}$, or $1 \mu \mathrm{mol} / \mathrm{L}$ BACE inhibitor IV (Calbiochem, Billerica, MA) for 12 hours, followed by treatment with $10 \mu \mathrm{mol} / \mathrm{L}$ ritonavir or vehicle (DMSO) for 16 hours, at which time media were collected. For rat neuroglial cultures, cells were treated with combinations of antiretroviral drugs, followed by media collection at 4 and 16 hours.

\section{Human Soluble APP ELISAs}

Cell culture media from $\mathrm{CHO}$ cells stably expressing human wild-type APP were pretreated with $10 \mathrm{nmol} / \mathrm{L}, 100 \mathrm{nmol} / \mathrm{L}$, or $1 \mu \mathrm{mol} / \mathrm{L}$ BACE inhibitor IV for 12 hours, followed by treatment with $10 \mu \mathrm{mol} / \mathrm{L}$ ritonavir or DMSO vehicle for 16 hours, at which time media were collected. Conditioned media were then diluted 25-fold, and human soluble APP $\alpha$ $(\operatorname{sAPP} \alpha)$ and $\operatorname{sAPP} \beta$ levels were measured with human ELISA assays (IBL International, Toronto, ON, Canada), according to the manufacturer's recommendations.

\section{S Proteasome Activity Assay}

Whole cell lysates prepared from 21 DIV rat cortical neuroglial cultures treated with ritonavir, saquinavir, or lactacystin for 16 hours, as described above, were used to measure 20S proteasome activity (assay from Millipore), according to the manufacturer's recommendations. A total of $10 \mu \mathrm{g}$ protein per sample was used.

\section{Immunofluorescence Staining of Neuroglial Cultures}

To assess the neuroprotective effect of BACE1 inhibition, neuroglial cultures grown on coverslips were pretreated with $1 \mu \mathrm{mol} / \mathrm{L}$ BACE inhibitor IV for 30 minutes, followed by 12 hours treatment with $10 \mu \mathrm{mol} / \mathrm{L}$ ritonavir. Propidium iodide $(15 \mu \mathrm{mol} / \mathrm{L})$ was added to neuroglial cultures 15 minutes before the conclusion of treatments. Cultures were washed twice with phosphate-buffered saline (PBS) and fixed for 30 minutes with $4 \%$ paraformaldehyde $/ 4 \%$ sucrose in PBS, followed by permeabilization in $0.2 \%$ bovine serum albumin plus $0.1 \%$ Triton X-100 in PBS for 1 hour at room temperature. Coverslips were then washed twice with PBS and incubated with anti-MAP2 antibody $(1: 1000)$ in normal antibody diluent overnight at $4^{\circ} \mathrm{C}$. After washing in PBS-Tween 20, coverslips were incubated with a fluorescein isothiocyanate-conjugated goat anti-mouse IgG secondary antibody (1:200) for 30 minutes at room temperature. Coverslips were mounted onto slides, and the number of MAP2-positive cells was determined by blind counting of all fields ( 15 at $200 \times$; by P.J.G., N.S.K., and G.V.D.W.) in three adjacent vertical columns through the center of each coverslip. ${ }^{23}$ Images were captured using a Nikon Eclipse E400 fluorescent microscope (Nikon Corp., Tokyo, Japan) equipped with an Olympus DP70 digital camera (Olympus Corp., Tokyo, Japan). Propidium iodidepositive puncta were hand-counted using NIH ImageJ software program version 1.44 and were plotted as fold changes compared to untreated controls. Averages were expressed as means $\pm \mathrm{SEM}$.

\section{Pulse-Chase and Immunoprecipitation}

Primary rat neuroglial cultures were grown in $60-\mathrm{mm}$ dishes for 21 DIV in neurobasal media supplemented with B27. Cultures were pulse-labeled with $2 \mathrm{~mL}$ methionine/ cysteine-free Dulbecco's modified Eagle's medium containing $0.4 \mathrm{mCi}{ }^{35} \mathrm{~S}$-labeled methionine and cysteine for 30 minutes. Cultures were washed twice with sterile Dulbecco's PBS and chased with neurobasal media plus B27 with or without $10 \mu \mathrm{mol} / \mathrm{L}$ ritonavir. At $0,6,12,18$, and 24 hours after labeling, cultures were harvested with icecold lysis buffer $(50 \mathrm{mmol} / \mathrm{L}$ Tris, $\mathrm{pH} 7.5,120 \mathrm{mmol} / \mathrm{L}$ $\mathrm{NaCl}, 0.5 \% \mathrm{NP}-40$, and $0.4 \mathrm{mmol} / \mathrm{L} \mathrm{Na}_{3} \mathrm{VO}_{4}$, supplemented with protease inhibitors). Lysates were immunoprecipitated with Dynabeads Protein A (Thermo Fisher Scientific) and 2 $\mu \mathrm{g}$ anti-BACE1 (Cell Signaling Technology), run on a $4 \%$ to $12 \%$ Bis-Tris gradient gel for separation, and transferred onto polyvinylidene difluoride membranes for approximately 7 hours. Membranes were dried and exposed via autoradiography.

\section{Subcellular Fractionation}

To evaluate ATF4 nuclear translocation in response to antiretroviral drug treatments, 21 DIV rat neuroglial cultures were treated with $10 \mu \mathrm{mol} / \mathrm{L}$ ritonavir or vehicle (DMSO) for 16 hours, and cytoplasmic and nuclear fractions were prepared. Briefly, cultures were washed twice in ice-cold PBS and lysed for 10 minutes in cytoplasmic lysis buffer $(10 \mathrm{mmol} / \mathrm{L}$ HEPES, pH 7.9, $10 \mathrm{mmol} / \mathrm{L} \mathrm{KCL}, 10 \mathrm{mmol} / \mathrm{L}$ EDTA, $1 \mathrm{mmol} / \mathrm{L}$ dithiothreitol, and $0.4 \% \mathrm{NP}-40$, supplemented with protease inhibitors). Extracts were centrifuged at $4^{\circ} \mathrm{C}$ for 3 minutes at $15,000 \times g$, and cytoplasmic supernatants were stored at $-80^{\circ} \mathrm{C}$. The remaining nuclear pellets were resuspended in nuclear lysis buffer $(20 \mathrm{mmol} / \mathrm{L}$ HEPES, pH 7.9, 400 mmol/L NaCl, 1 mmol/L EDTA, 10\% glycerol, and $1 \mathrm{mmol} / \mathrm{L}$ dithiothreitol, with protease inhibitors) and incubated at $4^{\circ} \mathrm{C}$, with end-to-end rotation, for 2 hours. The nuclear supernatants were collected after centrifugation at $15,000 \times g$ for 5 minutes at $4^{\circ} \mathrm{C}$. Protein concentrations were determined using the Bradford method, and lysates were run on $4 \%$ to $12 \%$ Bis-Tris gradient gels. Membranes containing nuclear fractions were probed with rabbit anti-ATF4 antibody.

\section{Transfection Using Magnetic Nanoparticles}

Pure neuronal cultures at DIV 10, prepared as described above, were transfected with plasmid DNA via magnetofection using the Magnefect-Nano II system (Nanotherics). Briefly, $0.5,1$, or $2 \mu \mathrm{g}$ of the following plasmid DNAs were complexed with $2.4 \mu \mathrm{L}$ of Neuromag transfection reagent (Nanotherics) for 15 to 20 minutes in serum-free neurobasal 
media: pcDNA3.1Zeo ${ }^{+} / \mathrm{BACE} 15^{\prime}$ UTR, $\mathrm{pcDNA3} 1 \mathrm{Zeo}^{+} /$ BACE1- $\Delta 5^{\prime}$ UTR (both generous gifts from Robert Vassar), pLenti CMV/TO Puro destination vector (backbone), pcDNA3.1Zeo ${ }^{+} /$wild-type mouse PERK, and pcDNA3.1Zeo ${ }^{+} /$PERK-K618A. Complexes were added drop-wise to 24-well plates of pure neuronal cultures containing 500,000 cells per well, and plates were incubated for 30 minutes at $37^{\circ} \mathrm{C}$ with $5 \% \mathrm{CO}_{2}$ over a magnet array oscillating at $3 \mathrm{~Hz}$ with $0.2-\mathrm{mm}$ amplitude of displacement. At the end of magnetofection, plates were removed from the magnet array and were processed after 48 to 72 hours for either immunoblotting or cell staining, following routine methods.

\section{Statistical Analysis}

All data were analyzed with Prism software version 5.0 (GraphPad Software, San Diego, CA). All quantifications were expressed as means \pm SEM. Paired results were analyzed by Mann-Whitney $U$ test or unpaired $t$-test, and data with multiple categories were analyzed by one-way analysis of variance plus Newman-Keuls or Dunnett post hoc test, as indicated. $P<0.05$ was considered significant for all statistical analyses performed.

\section{Results}

\section{ARVs Induce Axonal Damage and UPR in Vivo}

Several clinical studies have reported an inverse relationship between ARV regimens that have high CNS penetration effectiveness scores and neurocognitive outcomes. ${ }^{53-55}$ However, it has been difficult to separate CNS toxicity induced by HIV from that of ARV. We previously showed that ARVs administered to SIV-infected pigtail macaques lead to decreases in markers of synaptodendritic integrity, including synaptophysin, in the hippocampus and calmodulin kinase II in the frontal cortex, compared to SIV-infected, placebo-treated, or uninfected controls. ${ }^{23}$ In this lentiviral-induced neurodegeneration model, ${ }^{41}$ adult pigtail macaques started receiving either a placebo or an ARV treatment (ART) that included tenofovir (NRTI), atazanavir (PI), saquinavir (PI), and L-870812a (integrase inhibitor) at 12 days after inoculation. Compared to $90 \%$ of placebo-treated animals that develop neurological disease within 12 weeks, ${ }^{41}$ those receiving ART did not develop SIV encephalitis nor did they demonstrate neurological dysfunction. ${ }^{43}$ Furthermore, they displayed a rapid reduction in plasma and cerebrospinal fluid viral loads and suppression of viral replication with conservation of $\mathrm{CD}^{+}$ T-cell counts until elective euthanasia at day 160 after inoculation. To expand on our previous findings, we used immunofluorescence and immunoblotting to retrospectively assess formalin-fixed, paraffin-embedded hippocampal tissue from this cohort to determine APP expression. Accumulation of APP along axons was reported in previous studies on various neuroinflammatory diseases as well as trauma ${ }^{56-58}$; thus, we assessed APP levels as a neuronal response to damage. Consistent with our previous findings, we found that APP expression was significantly elevated in the $\mathrm{SIV}^{+} / \mathrm{ART}$ group than the $\mathrm{SIV}^{+} /$placebo and $\mathrm{SIV}^{-}$control groups (Figure 1, A and B). Interestingly, placebo-treated animals showed a reduction in hippocampal APP levels compared to uninfected controls. These changes were corroborated by immunoblotting of total APP (Figure 1, C and F). We also observed increased $\mathrm{BiP}$ expression in $\mathrm{SIV}^{+} /$placebo animals compared with $\mathrm{SIV}^{-}$controls, but no statistically significant change in the $\mathrm{SIV}^{+} / \mathrm{ART}$ group (Figure 1D). More important, the $\mathrm{SIV}^{+} / \mathrm{ART}$ macaques displayed a significant increase in BACE1 compared to both $\mathrm{SIV}^{+} /$ placebo and uninfected controls (Figure 1E), in agreement with previous observations of accumulation of APP species in the CNS of HIV-infected individuals. ${ }^{5,9,59,60}$ In contrast, p-eIF2 $\alpha$ levels were elevated only in the $\mathrm{SIV}^{+} /$ placebo macaques and not in the ART-treated animals (Figure 1G).

Samples from cohorts of ARV-treated uninfected humans and matching ARV-treated $\mathrm{SIV}^{-}$macaques are not available. Therefore, to determine the contribution of ARVs to neuronal UPR activation and BACE1 upregulation in vivo independent of virus, we administered ritonavir or saquinavir i.v. to healthy adult mice for 2 weeks. Ritonavir and saquinavir doses were based on published pharmacokinetic ARV studies in rodents. ${ }^{46,48,61}$ In agreement with our previous studies in rats, animals displayed no overt signs of behavioral alterations or distress during the course of treatment. ${ }^{23}$ However, immunoblotting analysis revealed a statistically significant increase in BACE1 expression in the hippocampus in ritonavir- and saquinavir-treated mice compared with the vehicle-treated controls, complementing our findings in $\mathrm{SIV}^{+}$/ART macaques (Figure 2, A and B). ARV-treated mice also displayed significant increases in p-eIF $2 \alpha$ expression, whereas saquinavir-treated mice had elevated levels of $\mathrm{BiP}$ in the hippocampus compared to ritonavirand vehicle-treated animals. These data further support a role for ARV-associated UPR activation and BACE1 upregulation in the CNS.

\section{ARVs Activate the UPR and Up-Regulate BACE1 Expression}

We and others have shown that ARVs are toxic to primary neurons. ${ }^{23,24,62}$ Although it is suggested that such toxicity is mediated by mitochondrial DNA damage and/or prooxidant properties of these drugs, additional mechanisms may also contribute to ARV-mediated neuronal damage and death. Given the established role of PIs inducing ER stress in numerous cell types, including macrophages and hepatocytes, ${ }^{17}$ we hypothesized that ARV drugs may be activating the UPR in neurons. Therefore, we examined canonical UPR markers in primary rat neuroglial cultures in 


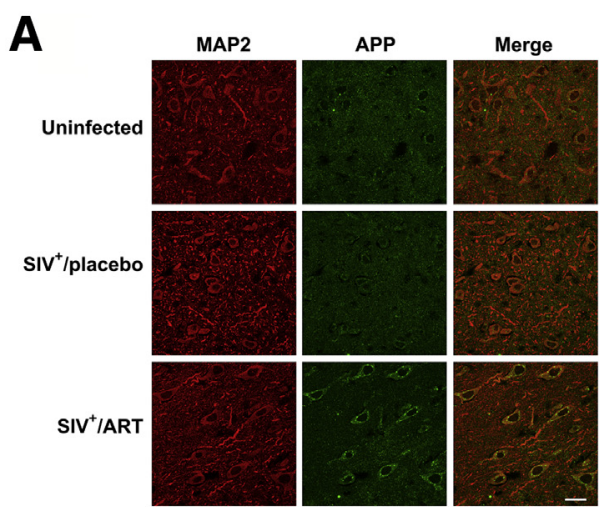

C

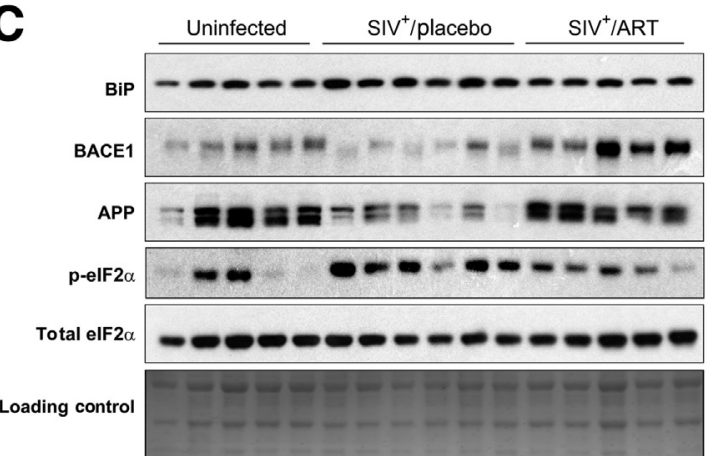

E
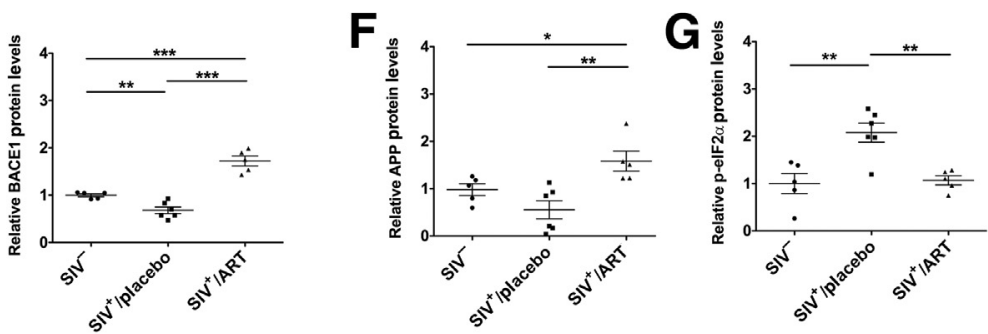

B

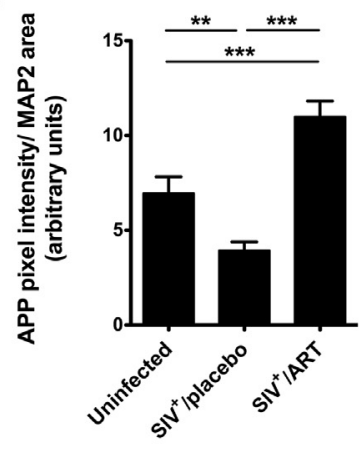

D

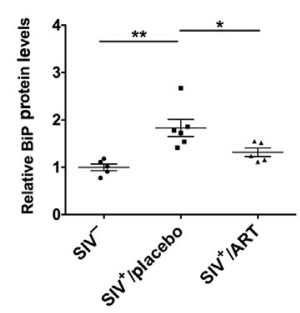

Figure 1 ARV drugs induce APP and CNS damage in $\mathrm{SIV}^{+}$macaques. Pigtail macaques were either uninfected, $\mathrm{SIV}^{+} /$placebo treated, or SIV $\mathrm{SI}^{+}$antiretroviral therapy (ART) treated. Double-label confocal microscopy was used to capture images of hippocampal brain sections labeled for MAP2 (red) and APP (green). A: Representative images of one case per group stained with APP and MAP2 are shown. B: Quantification shows a significant increase in intraneuronal APP in $\mathrm{SIV}^{+} / \mathrm{ART}$ macaques compared to uninfected as well as $\mathrm{SIV}^{+} /$placebo controls. C: Fresh-frozen tissue sections of hippocampi from these animals were immunoblotted. Fast green was used as a loading control. D-G: Quantification of band densities from immunoblots shown in C. Data represent means \pm SEM (B, C, $\mathbf{D}-\mathbf{G}$ ). $n=5$ (uninfected and $\mathrm{SIV}^{+} /$ART-treated macaques); $n=6\left(\mathrm{SIV}^{+} /\right.$placebo-treated macaques). ${ }^{*} P<0.05,{ }^{*} P<0.01$, and ${ }^{* * *} P<0.001$ (one-way analysis of variance, Newman-Keuls post hoc). Scale bar $=20 \mu \mathrm{m}(\mathbf{A})$. response to increasing concentrations of AZT, saquinavir, or ritonavir (Figure 3A). Drug dose ranges used in our in vitro studies were based on reported plasma and cerebrospinal fluid levels of ARVs. ${ }^{63,64}$ At 16 hours after treatment with ritonavir or saquinavir, neuroglial cultures displayed a fivefold increase in BiP expression and more than a fourfold increase in p-eIF2 $\alpha$ (Figure 3, B and C). AZT treatment $(25 \mu \mathrm{mol} / \mathrm{L})$ resulted in a threefold increase in BiP expression but did not significantly alter $\mathrm{p}$-eIF2 $\alpha$. As an added parameter to ensure the presence of ARV-mediated UPR activation, we treated primary neuroglial cultures with $10 \mu \mathrm{mol} / \mathrm{L}$ ritonavir, $1 \mu \mathrm{mol} / \mathrm{L}$ saquinavir, $25 \mu \mathrm{mol} / \mathrm{L} \mathrm{AZT}$, or $1 \mu \mathrm{mol} / \mathrm{L}$ thapsigargin (positive control) for 16 hours and assessed the levels of spliced $\mathrm{X}$ box binding protein (XBP)1 relative to unspliced XBP-1 by TaqMan quantitative RT-PCR (Figure 3G). We observed nearly a twofold increase in spliced XBP-1 mRNA in ritonavir- and saquinavirtreated cultures, but no change in AZT-treated neurons, compared to vehicle controls.

Recent studies have shown that induction of ER stress in neurons could increase protein expression of the APPcleaving enzyme, BACE1. ${ }^{36,65}$ Therefore, we sought to determine whether ARV-treated neuroglial cultures, which showed robust activation of ER stress, displayed changes in BACE1 expression. Immunoblotting analysis revealed that 16-hour treatment with AZT, saquinavir, or ritonavir resulted in fourfold to fivefold increases in BACE1 expression (Figure 3D). To rule out the possibility of species-specific effects, we also treated 21 DIV human fetal neurons with increasing doses of AZT, saquinavir, and ritonavir for 16 hours and found similar, albeit statistically insignificant, changes in both BACE1 and BiP expression in saquinavir- and ritonavir-treated cultures (Figure 3, $\mathrm{H}-\mathrm{K}$ ).

In addition to BACE1, APP may be cleaved by two additional secretases, $\gamma$-secretase and $\alpha$-secretase, the latter of which cleaves APP to preclude A $\beta$ production. To examine whether ARVs affect the expression of $\alpha$ - and/or $\gamma$-secretases, we also immunoblotted for presenilin-1 C-terminal fragment $(\gamma$-secretase) and mature ADAM metalloproteinase domain $10(\alpha$-secretase) (Figure 3A). We found no significant changes in the expression of either of these enzymes regardless of drug treatment or dose (Figure 3, E and F). Taken together, these data indicate that antiretroviral drugs, and PIs in particular, induce UPR and BACE1 in neurons. 


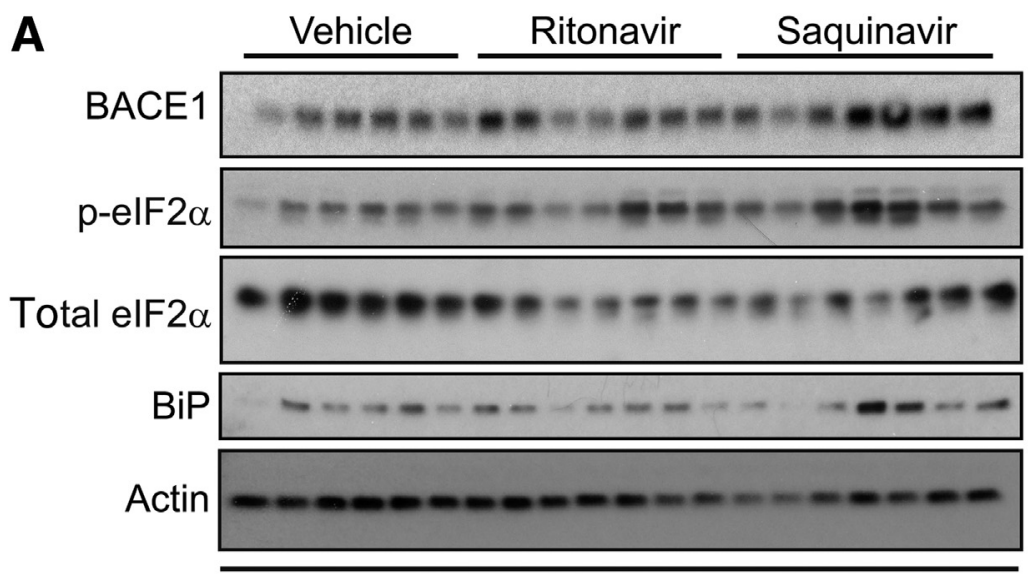

B
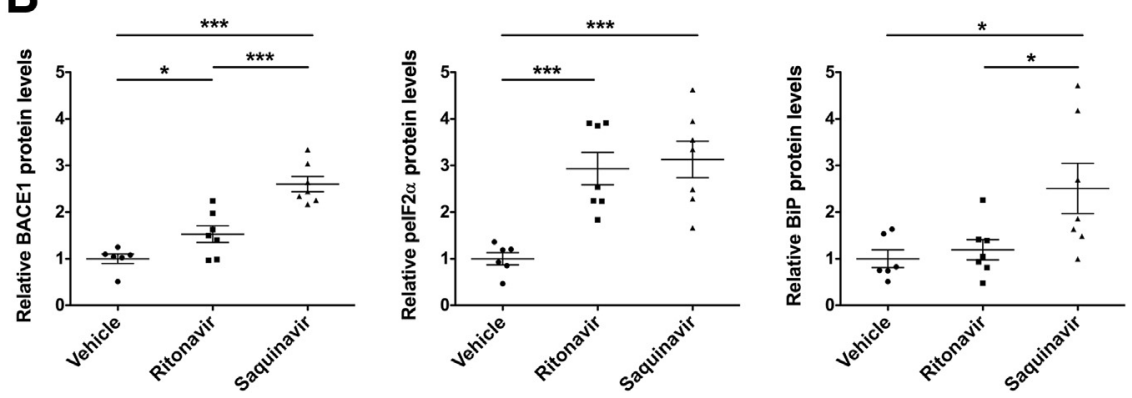

Figure 2 ARV drugs induce the UPR and BACE1 in the CNS independent from immunodeficiency virus. Adult male $\mathrm{C} 57 \mathrm{BL} / 6$ mice catheterized through the jugular vein were administered one the following: dimethyl sulfoxide (DMSO), $20 \mathrm{mg} / \mathrm{kg}$ ritonavir, or $25 \mathrm{mg} / \mathrm{kg}$ saquinavir twice daily for 14 days by continuous i.v. injection. A: Hippocampal brain lysates were immunoblotted, and actin was used as a loading control. B: Densitometric analysis revealed significant increases in BACE1 and p-eIF2 $\alpha$ levels in both ritonavir- and saquinavir-treated mice versus vehicle controls, whereas BiP was elevated only in saquinavir-treated mice. Data represent means \pm SEM (B). $n=6$ (DMSO-treated mice); $n=7$ (ritonavir- and saquinavir-treated mice). ${ }^{*} P<0.05,{ }^{* * *} P<0.001$ (one-way analysis of variance, Newman-Keuls post hoc).

\section{Ritonavir Increases BACE1 Processing of APP in Primary Neurons}

Based on our observation that ARVs induce BACE1 expression in neuroglial cultures, we sought to determine whether this translated into functional changes in BACE1's enzymatic activity by assessing APP processing. To that end, we treated $\mathrm{CHO}$ cells that are stably expressing human APP with $10 \mu \mathrm{mol} / \mathrm{L}$ ritonavir, as a representative PI, for 16 hours and measured the relative amount of $A \beta$ species in the culture media using a commercially available human/rat $\mathrm{A} \beta_{40^{-}}$or $\mathrm{A} \beta_{42^{-}}$-specific sandwich ELISA. Although ritonavir had no effect on secreted $A \beta_{40}$ levels, $A \beta_{42}$ levels were increased by nearly twofold (Figure 4A). In addition, pretreatment with a cell-permeable BACE1 inhibitor blocked ritonavir-mediated increases in $\mathrm{A} \beta_{42}$ in a dose-dependent manner. These findings differ from previous reports that changes in BACE1 activity affect the generation of all $A \beta$ isoforms equally. ${ }^{66}$ To further understand how ritonavir may be affecting human APP processing, CHO culture media were measured for $\operatorname{sAPP} \beta$ and $\operatorname{sAPP} \alpha$ by ELISA (Figure 4, B and C). In contrast to the observed increases in $\mathrm{A} \beta_{42}$ peptide, no significant changes in $\mathrm{SAPP} \beta$ or $\mathrm{sAPP} \alpha$ were detected in culture media from ritonavir-treated $\mathrm{CHO}$ cells. We also used the human/rat $A \beta_{40^{-}}$or $A \beta_{42}$-specific sandwich ELISA to assess $A \beta_{40}$ and $A \beta_{42}$ release into the media of rat cortical neuroglial cultures treated with combinations of ARV drugs (Figure 4, D and E). At 4 hours after treatment, no changes were observed in secreted $A \beta_{40}$ or
$\mathrm{A} \beta_{42}$ peptides; however, at 16 hours after treatment, all ARV combinations resulted in 1.5- and 3-fold increases in $A \beta_{40}$ and $A \beta_{42}$ levels, respectively. In conjunction with our in vivo findings of increased $A \beta$ oligomers in HAND patients and increased APP in SIV-infected/ART-treated macaques, these findings suggest that ARVs promote BACE1 processing of APP in CNS neurons.

\section{BACE1 Inhibition Prevents MAP2 Loss in Ritonavir- Treated Neuroglial Cultures}

Several lines of evidence suggest that BACE1 may act as a stress response protein in the CNS. ${ }^{36,67,68}$ Therefore, we sought to determine whether BACE1 has a protective or deleterious effect on neuronal survival after chronic exposure to ritonavir. Primary rat cortical cultures were pretreated with vehicle (DMSO) or $1 \mu \mathrm{mol} / \mathrm{L}$ BACE1 inhibitor for 30 minutes, followed by $10 \mu \mathrm{mol} / \mathrm{L}$ ritonavir for 48 hours. Cultures were labeled with propidium iodide to assess cellular viability and immunostained for MAP2 and synapsin. BACE1 inhibition had no effect on $\mathrm{MAP}^{+}$cell count, synapsin intensity, or propidium iodide uptake compared with untreated and vehicle controls (Figure 5A). Forty-eight hour ritonavir treatment resulted in a threefold decrease in $\mathrm{MAP}^{+}$cell count and nearly a threefold increase in propidium iodide uptake, but no change in synaptic integrity relative to MAP2 area in 10 DIV neuroglial cultures (Figure 5, A-D). More important, pretreatment with BACE1 inhibitor rescued $\mathrm{MAP2}^{+}$cell loss in ritonavir-treated 


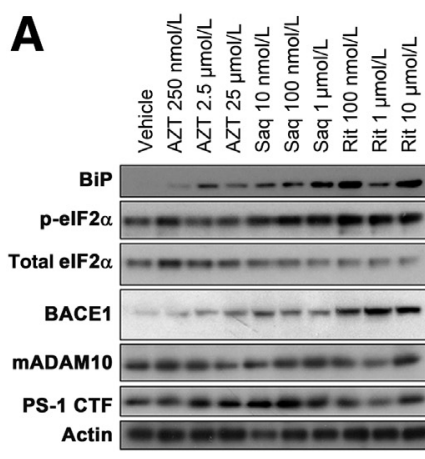

D

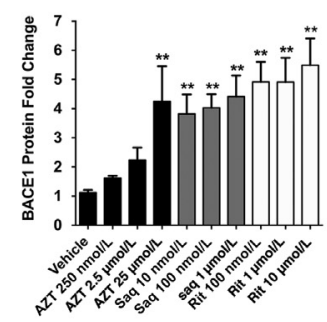

B

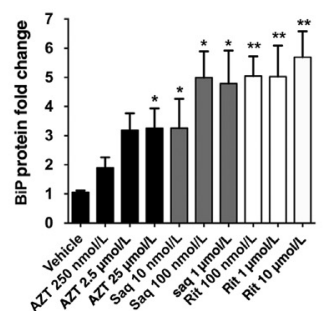

E

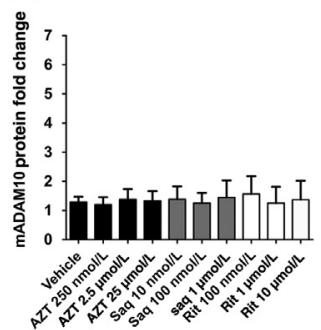

C

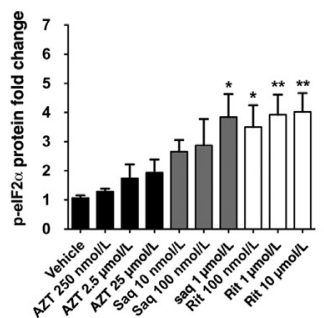

$\mathbf{F}$

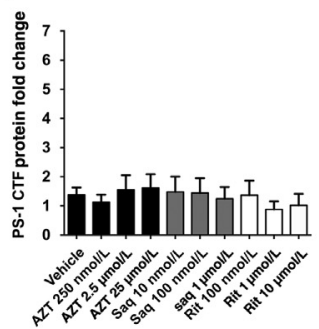

G

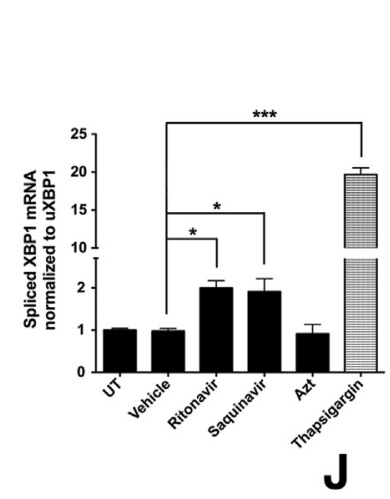

H

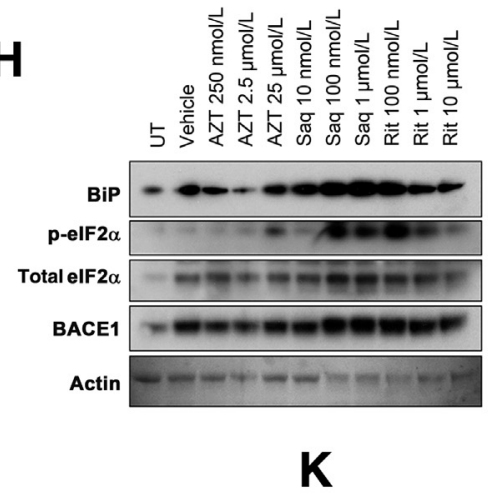

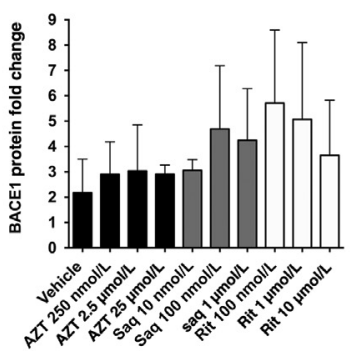
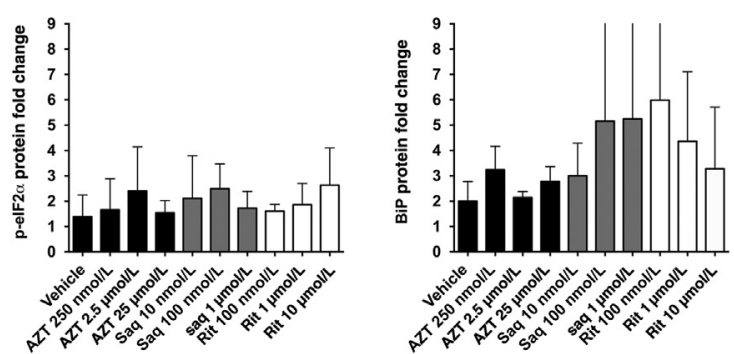

Figure 3 ARV drugs activate the UPR and up-regulate BACE1 expression in primary neurons. A: Twenty-one DIV rat neuroglial cultures treated with ARVs for 16 hours were immunoblotted. Actin was used as a loading control for all targets, except p-eIF2 $\alpha$, which was normalized to total eIF2 $\alpha$. Representative blots shown. B-F: Quantification of band intensities was normalized to actin and expressed as fold changes relative to vehicle. BiP, p-eIF2 $\alpha$, and BACE1 protein levels were significantly elevated compared to controls. A disintegrin and metalloprotease 10 (ADAM10) and presenilin-1 C-terminal fragment (PS-1 CTF) did not show any significant changes. G: Rat neurons were treated with $0.04 \%$ dimethyl sulfoxide (DMS0; Vehicle), $10 \mu \mathrm{mol} / \mathrm{L}$ ritonavir (Rit), $1 \mu \mathrm{mol} / \mathrm{L}$ saquinavir (Saq), $25 \mu \mathrm{mol} / \mathrm{L}$ zidovudine (AZT), or $1 \mu \mathrm{mol} / \mathrm{L}$ thapsigargin for 16 hours. Total mRNA was isolated, and expression levels of spliced $X$ box binding protein (XBP)-1 mRNA were measured via TaqMan using the comparative $\mathrm{Ct}$ $(\Delta \Delta C \mathrm{C})$ method relative to unspliced XBP1. Quantitative RT-PCR assays were performed in triplicate. Both ritonavir and saquinavir induced significant increases in spliced XBP1. H: Twenty-one DIV human fetal neurons were treated as in $\mathbf{A}$, and lysates were immunoblotted. One representative blot is shown. I-K: Quantification of band intensities was normalized to actin and expressed as fold changes relative to vehicle. All values represent means \pm SEM (B-G, and $\mathbf{I}-\mathbf{K}) . n=5(\mathbf{B}-\mathbf{F}$, vehicle: $0.04 \%$ DMSO); $n=4(\mathbf{G}) ; n=3(\mathbf{H})$. ${ }^{*} P<0.05,{ }^{* *} P<0.01$, and ${ }^{* * * P}<0.001$ (one-way analysis of variance, Dunnett post hoc). UT, untreated. neurons and decreased propidium iodide uptake (Figure 5D). Together, these results suggest BACE1 may contribute to PI-mediated neuronal damage and death.

\section{Ritonavir Up-Regulates BACE1 Expression in a Translation-Dependent Manner}

Vassar and colleagues ${ }^{35,36}$ first reported that chronic activation of the UPR results in translational up-regulation of BACE1. To determine whether ARVs increase BACE1 expression by altering mRNA levels, we first treated 21 DIV rat neuroglial cultures with ritonavir, saquinavir, AZT, or thapsigargin for 16 hours and harvested mRNA for quantitative RT-PCR. We observed no changes in BACE1 mRNA in any of the ARV-treated cultures compared to controls; however, there was a significant decrease in BACE1 mRNA in thapsigargin-treated neuroglial cultures (Figure 6A). To confirm that BACE1 regulation is occurring via a posttranscriptional mechanism, we pretreated neuroglial cultures with a translation inhibitor, anisomycin, or a transcription inhibitor, actinomycin $\mathrm{D}$, for 12 hours, followed by 16 hours treatment with ritonavir, and harvested protein lysates for analysis by immunoblotting for BACE1. Inhibition of transcription with $5 \mu \mathrm{mol} / \mathrm{L}$ actinomycin D did not affect 

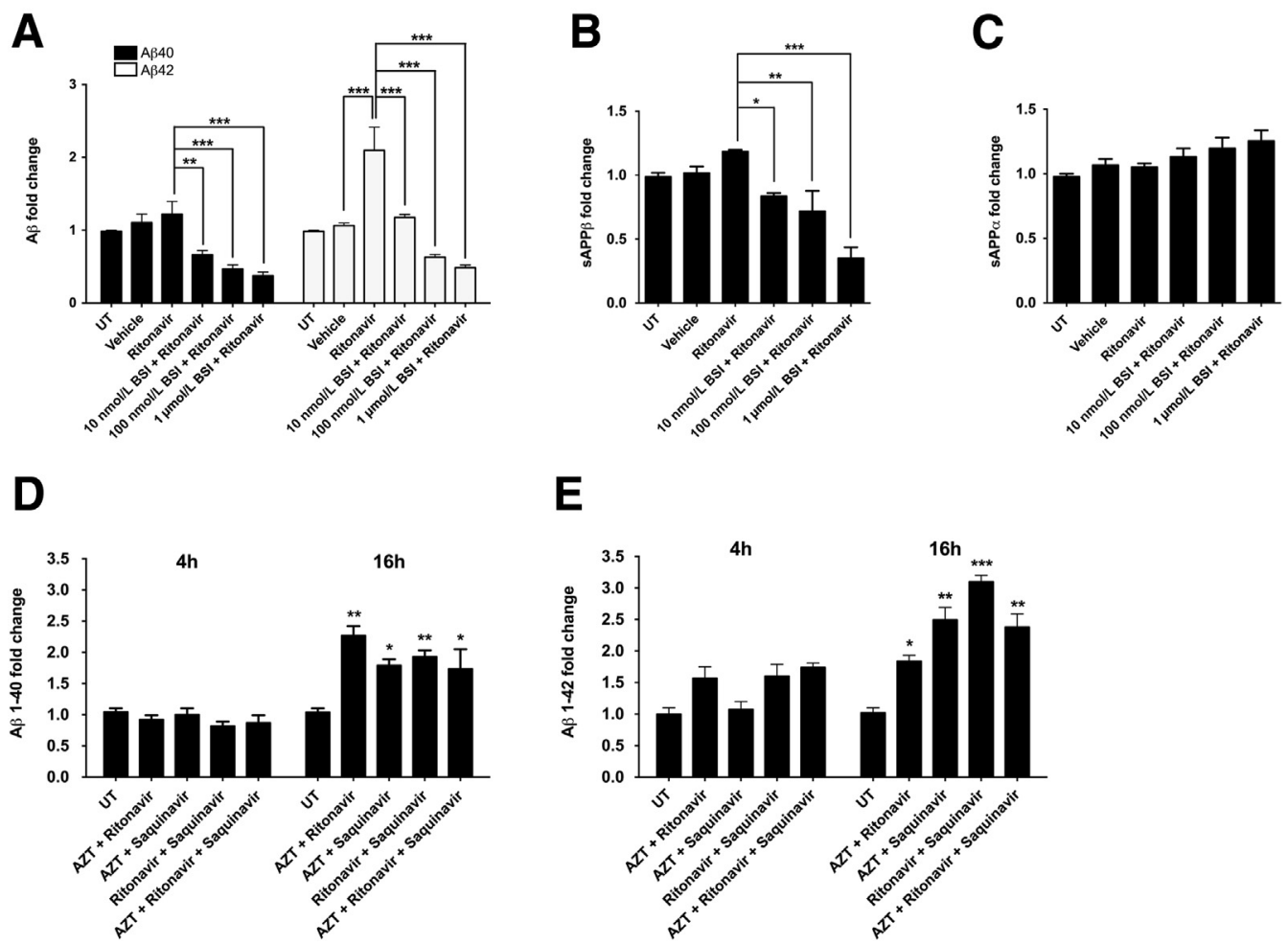

Figure 4 ARV drugs increase BACE1 processing of APP in primary neurons. Chinese hamster ovary cells stably expressing human APP were either treated with $10 \mu \mathrm{mol} / \mathrm{L}$ ritonavir alone for 16 hours or pretreated with increasing doses of a cell-permeable BACE1 inhibitor (BSI) for 12 hours before ritonavir treatment. Culture media were analyzed with a human/rat $A \beta_{42^{-}}$or $A \beta_{40}$-specific sandwich enzyme-linked immunosorbent assay (ELISA; $A$ ) or a human sAPP $\alpha$ or SAPP $\beta$ ELISA (B and C). A: Ritonavir led to a twofold increase in $A \beta_{42}$ production that was dose-dependently blocked by BSI, whereas $A \beta_{40}$ levels were not affected by ritonavir. No statistically significant changes in SAPP $\beta$ (B) or SAPP $\alpha$ (C) were observed in ritonavir-treated cultures, although sAPP $\beta$ was dose-dependently decreased with BSI. D and E: Primary rat neuroglial cultures were treated with various ARV combinations [10 $\mu \mathrm{mol} / \mathrm{L}$ ritonavir, $1 \mu \mathrm{mol} / \mathrm{L}$ saquinavir, and $25 \mu \mathrm{mol} / \mathrm{L}$ zidovudine (AZT)] for 4 or 16 hours. Culture media were analyzed with a human/rat A $\beta_{42^{-}}$or A $\beta_{40^{-}}$specific sandwich ELISA, as in $\mathbf{A}$. At 16 hours, both $A \beta_{42}$ and $A \beta_{40}$ levels were increased in most treatment conditions. AZT appeared to blunt PI-mediated enhancement of APP processing in combination treatment. All values represent means \pm SEM. $n=6(\mathbf{A}-\mathbf{C}) ; n=3(\mathbf{D}-\mathbf{F}) .{ }^{*} P<0.05,{ }^{* *} P<0.01$ (one-way analysis of variance, Dunnett post hoc), ${ }^{* *} P<0.001$ (one-way analysis of variance, Newman-Keuls post hoc). UT, untreated.

up-regulation of BACE1 protein levels by ritonavir; however, translation inhibition by 10 or $50 \mu \mathrm{mol} / \mathrm{L}$ anisomycin abrogated ritonavir-mediated BACE1 protein up-regulation (Figure 6, B and C), indicating that PIs are exerting their effects on neuronal BACE1 expression through either a translational or a post-translational mechanism.

ATF4 is a canonical target of translational control by p-eIF2 $\alpha$. Similar to BACE1, ATF4 mRNA contains multiple upstream open reading frames in its $5^{\prime}$ UTR, which act to suppress translation under basal conditions, but undergo scan-through after phosphorylation of $\operatorname{eIF} 2 \alpha$, leading to selective translational up-regulation during conditions of ER stress. ${ }^{36,65,69}$ ATF4 subsequently translocates to the nucleus to up-regulate the expression of genes involved in the UPR. Thus, we determined whether ATF4 was increased in the nucleus of ritonavir-treated neuroglial cultures after 16 hours of treatment. We observed nearly a fivefold increase in nuclear ATF4 in ritonavir- and thapsigargintreated neuroglial cultures, whereas cytoplasmic levels remained unchanged (Figure 6, D and E). Similarly, BACE1 expression was increased greater than twofold in the cytoplasm of ritonavir-treated cultures (Figure 6, D and E).
To confirm that translational control of BACE1 is occurring through its $5^{\prime}$ UTR, we transfected rat cortical neuroglial cultures with vectors containing full-length human BACE1 with the $5^{\prime}$ UTR $\left(+5^{\prime}\right.$ UTR) or without the $5^{\prime}$ UTR $\left(-5^{\prime}\right.$ UTR). We then treated cultures with DMSO or ritonavir for 16 hours. Similar to our wild-type rat cortical cultures, the neurons transfected with $+5^{\prime}$ UTR/ BACE1 cDNA displayed nearly a threefold increase in BACE1 expression after treatment with ritonavir compared to vehicle controls (Figure 6F). Deletion of the $5^{\prime}$ UTR resulted in a significant increase in overall BACE1 expression in transfected cells, as described previously ${ }^{36,70}$; however, overexpression of the $-5^{\prime}$ UTR/BACE1 construct prevented ritonavir-mediated up-regulation of BACE1 in neurons (Figure 6, F and G). We also assessed whether a PImediated increase in BACE1 occurred via proteasome inhibition, based on previous studies on dividing cells. ${ }^{19,71-73}$ As seen in Figure $6 \mathrm{H}$, compared to cultures treated with the proteasome inhibitor lactacystin, neither ritonavir nor saquinavir led to proteasome inhibition in neuroglial cultures after 16 hours, providing further evidence for the translational control of BACE1 in neurons exposed to these PIs. 
A
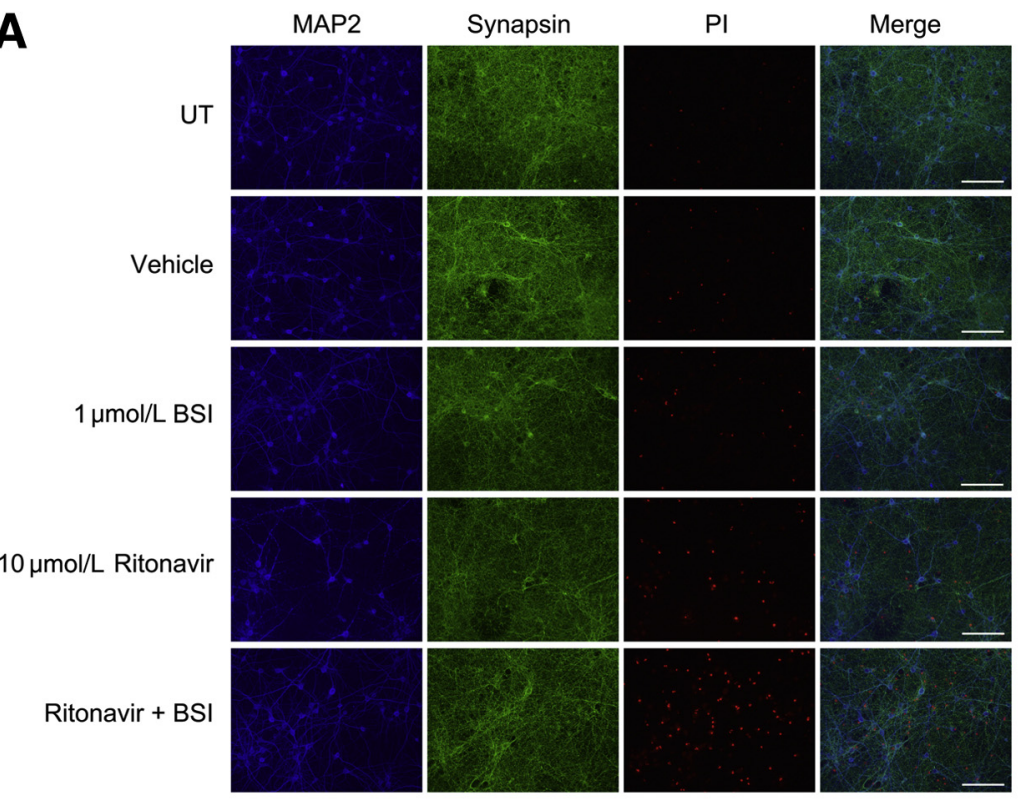

Merge
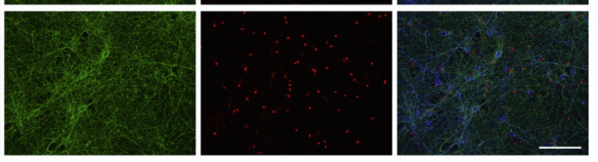

B
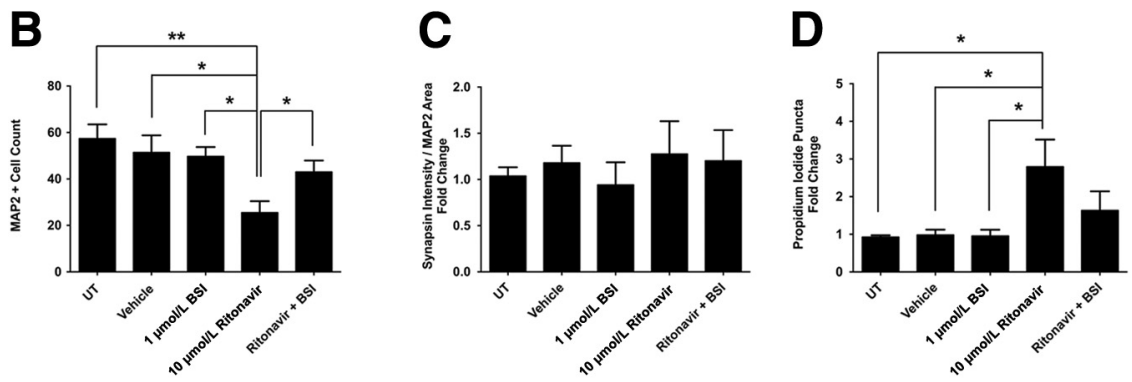

Figure 5 BACE1 inhibition prevents MAP2 loss in ritonavir-treated neurons. A: Ten DIV rat cortical cultures on coverslips were treated with dimethyl sulfoxide vehicle or $1 \mu \mathrm{mol} / \mathrm{L}$ BACE1 inhibitor (BSI) for 30 minutes before $10 \mu \mathrm{mol} / \mathrm{L}$ ritonavir treatment for 48 hours. Cultures were labeled with propidium iodide (red) and immunostained for MAP2 (blue) and synapsin (green). B-D: Ritonavir-treated neurons that were pretreated with $1 \mu \mathrm{mol} / \mathrm{L}$ BSI showed a significant increase in $\mathrm{MAP2}^{+}$cell number and a small decrease in propidium iodide staining. No changes in synapsin were observed between treatment groups. Representative images captured with epifluorescence microscopy are shown. $n=4$ (B-D). ${ }^{*} P<0.05,{ }^{*} P P<0.01$ (one-way analysis of variance, Newman-Keuls post hoc). Scale bar $=50 \mu \mathrm{m}(\mathbf{A})$. Original magnification, $\times 40(\mathrm{~A})$. UT, untreated.
To rule out the involvement of a post-translational mechanism in BACE1 up-regulation by ritonavir, we performed a pulse-chase experiment using ${ }^{35} \mathrm{~S}$-metabolic radiolabeling to determine the half-life of BACE1 in ritonavir-treated neuroglial cultures compared to vehicle controls. After confirming immunoprecipitation of BACE1 from neurons (Figure 7A), we pulse-labeled 21 DIV neuroglial cultures for 30 minutes and then chased with neurobasal media with or without $10 \mu \mathrm{mol} / \mathrm{L}$ ritonavir for up to 24 hours (Figure 7B). Compared to controls, we observed no apparent difference in BACE1 half-life in ritonavir-treated neuroglial cultures over the course of 24 hours (Figure $7 \mathrm{C}$ ). In both treatment conditions, we observed that BACE1 half-life was approximately 12 hours, similar to what has been reported previously. ${ }^{36,74}$ Collectively, these data strongly suggest that ritonavir-mediated up-regulation of BACE1 in neurons occurs through a $5^{\prime}$ UTR-dependent translational mechanism.

\section{PERK Is Necessary for ARV-Mediated BACE1 Up-Regulation in Neurons}

Several reports have proposed a role for p-eIF $2 \alpha$ in posttranscriptional regulation of $\mathrm{BACE} 1$ under conditions of oxidative and ER stress. ${ }^{36,65,75-77}$ However, eIF2 $\alpha$ can be phosphorylated by one of four kinases (PERK, PKR, heme-regulated inhibitor kinase, and general control nonderepressible 2), depending on the type of stress impinging on cells. Given that PERK is the central kinase responsible for eIF $2 \alpha$ phosphorylation under conditions of ER stress, we assessed whether PERK was involved in the stress response signaling in neuroglial cultures treated with ARVs. To that end, we generated neuroglial cultures from brains of tamoxifen-inducible cre recombinase conditional PERK knockout embryonic mice. At DIV 10, neuroglial cultures were treated with $100 \mathrm{nmol} / \mathrm{L}$ or $1 \mu \mathrm{mol} / \mathrm{L}$ 4-hydroxytamoxifen to excise the PERK gene. ${ }^{52}$ The estimated efficiency of PERK excision in neurons was approximately $50 \%$ to $60 \%$ after 96 hours of 4-hydroxytamoxifen treatment (Figure 8A). Wild-type and PERK-excised neurons were treated with $10 \mu \mathrm{mol} / \mathrm{L}$ ritonavir or $1 \mu \mathrm{mol} / \mathrm{L}$ saquinavir for 16 hours. As shown in Figure 8, $\mathrm{B}$ and $\mathrm{C}$, PERK-excised neuroglial cultures treated with ritonavir or saquinavir displayed reduced p-eIF2 $\alpha$ and BACE1 compared to wild-type cultures treated with the same drugs. These findings indicate that ARV-mediated BACE1 up-regulation in neuroglial cultures is dependent on UPR signaling through PERK. 
A

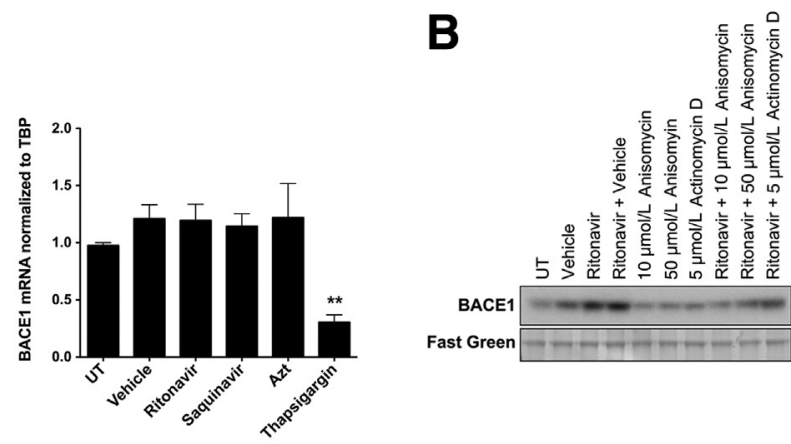

D

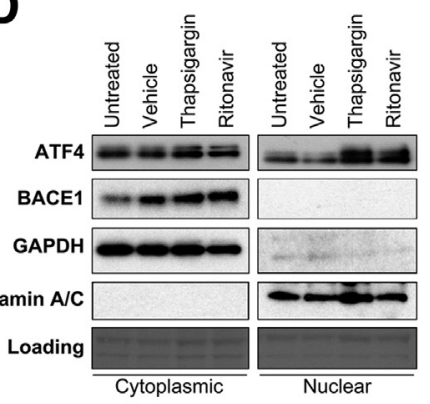

$\mathbf{F}$

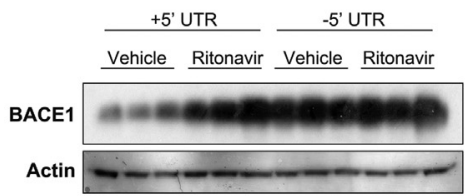

E

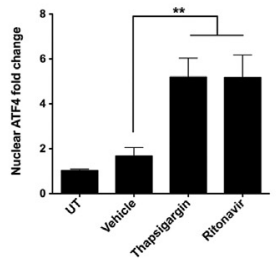

G

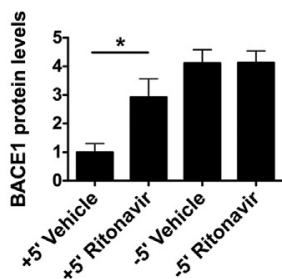

C

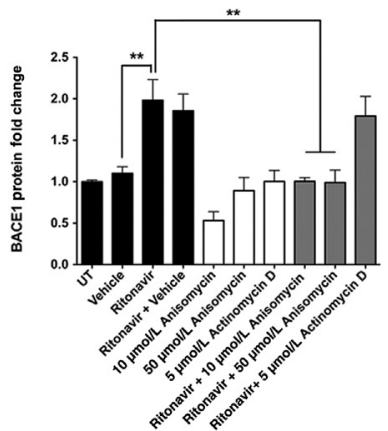

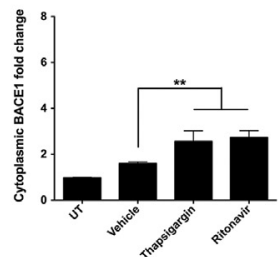

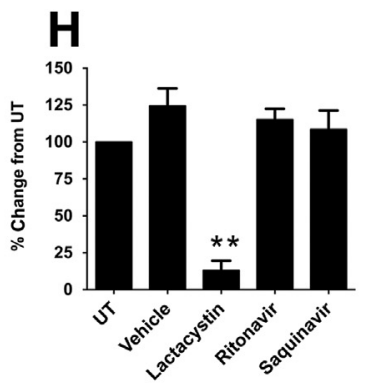

Figure 6 Ritonavir up-regulates neuronal BACE1 expression via translation-dependent control. A: Rat neurons were exposed to indicated treatments for 16 hours. BACE1 mRNA was determined using the $\Delta \Delta$ Ct method relative to TATA-Box binding protein (TBP). Quantitative RT-PCR assays were performed in triplicate (one-way analysis of variance, Dunnett post hoc). B: Rat neurons were either treated with ritonavir alone or pretreated with anisomycin or actinomycin D for 12 hours before ritonavir. Fast green was used as a loading control. C: Compared to ritonavir-only treated neurons, anisomycin pretreatment resulted in decreased BACE1 expression (one-way analysis of variance, Newman-Keuls post hoc). D: Rat neurons were treated for 16 hours, and cytoplasmic and nuclear fractions were analyzed by immunoblotting. E: Densitometric analysis revealed a significant increase in activating transcription factor 4 (ATF4) and BACE1 (one-way analysis of variance, Dunnett post hoc). F: Fourteen DIV rat cortical cultures were transfected with pcDNA3.1Zeo ${ }^{+}$vector containing full human BACE1 coding region, including the BACE1 $5^{\prime}$ UTR but missing the $3^{\prime}$ UTR $\left(+5^{\prime}\right.$ UTR), or pCDNA3.1Zeo ${ }^{+}$vector containing human BACE1 coding region, including the $3^{\prime}$ UTR but missing the $5^{\prime}$ UTR ( $-5^{\prime}$ UTR). Forty-eight hours later, cultures were treated with dimethyl sulfoxide or $10 \mu \mathrm{mol} / \mathrm{L}$ ritonavir for 16 hours, and immunoblotted for BACE1. Representative blots are shown. G: Quantification of BACE1 was normalized to actin (one-way analysis of variance, Newman-Keuls post hoc). H: Rat neurons were treated with $10 \mu \mathrm{mol} / \mathrm{L}$ ritonavir, $1 \mu \mathrm{mol} / \mathrm{L}$ saquinavir, or $10 \mu \mathrm{mol} / \mathrm{L}$ lactacystin for 16 hours. Whole cell lysate $(10 \mu \mathrm{g})$ from each condition was used to determine 20 S proteasome activity (one-way analysis of variance, Dunnett post hoc). $n=4(\mathbf{A}, \mathbf{C}$, and $\mathbf{E}) ; n=3(\mathbf{B}) ;$ $n=2(\mathbf{H}) .{ }^{*} P<0.05,{ }^{*} P<0.01$. GAPDH, glyceraldehyde-3-phosphate dehydrogenase; UT, untreated.

\section{Discussion}

The unanticipated persistence of neurocognitive deficits in $\mathrm{HIV}^{+}$patients is a growing public health concern as the average age of patients in the United States is expected to be $>50$ years by $2015 .{ }^{78}$ Mounting clinical and experimental evidence suggests ARV-mediated neurotoxicity; however, potential mechanisms remain elusive. Previously, we have reported ARV-mediated reactive oxygen species production in primary neurons, leading to activation of the endogenous antioxidant response. ${ }^{23}$ Our findings in this study provide a mechanistic link between ARV-mediated UPR in neurons and increased BACE1 in the CNS of mice and SIV-infected, ART-treated macaques.

We herein show, for the first time, that ARVs, PIs in particular, activate the UPR in primary rat neuroglial cultures as well as human fetal neurons. We also observed increased nuclear ATF4, indicating functional changes in the translational profile of neurons as a result. The specific mechanism by which PIs and NRTIs activate the UPR in neurons, albeit unclear, is likely multifactorial. In other cell types, PIs induce UPR via proteasome inhibition and 

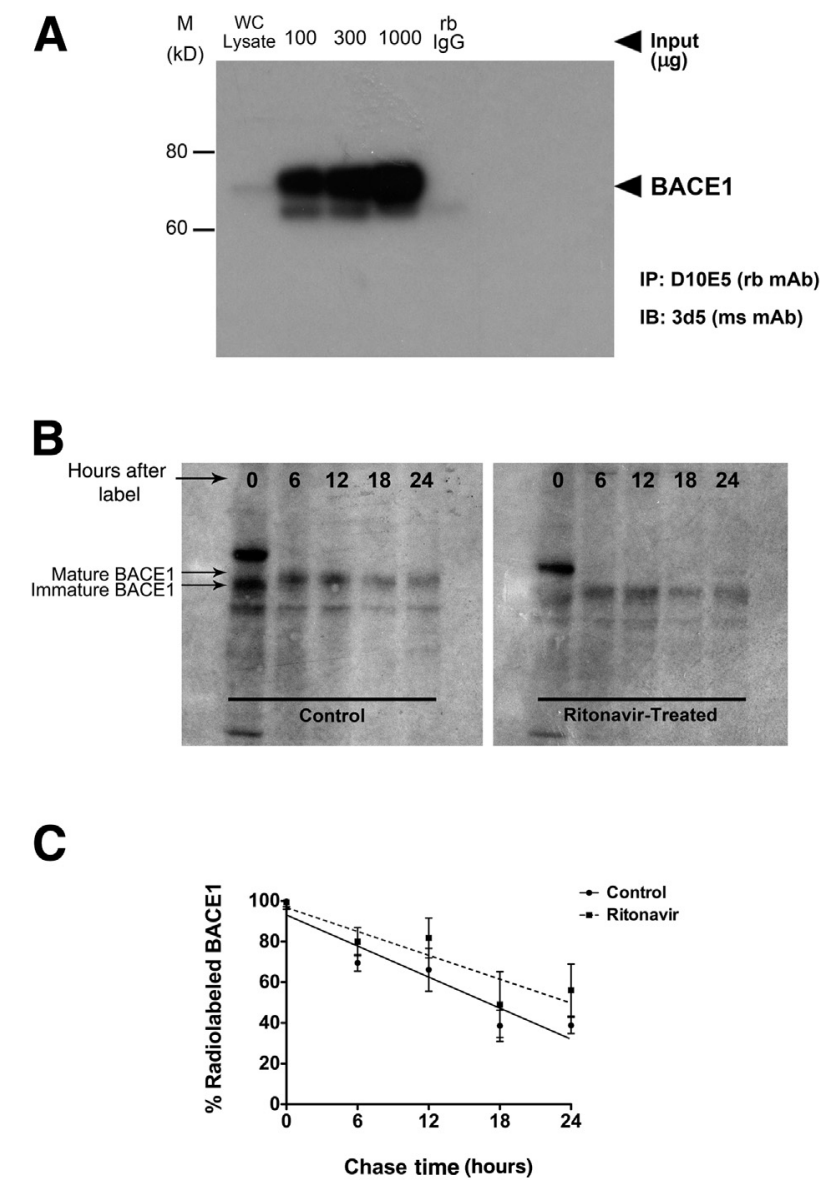

Figure 7 Ritonavir does not affect BACE1 protein stability in primary neurons. A: Primary rat neurons were pulse labeled for 30 minutes with ${ }^{35}$ S-methionine/cysteine-containing Dulbecco's modified Eagle's medium and chased with neurobasal media plus B27. Radiolabeled BACE1 was immunoprecipitated with Dynabeads Protein A and $2 \mu \mathrm{g}$ anti-BACE1 12 hours after labeling to confirm enrichment. B: Neurons were pulse labeled, as in $\mathbf{A}$, and chased with neurobasal media with or without $10 \mu \mathrm{mol} / \mathrm{L}$ ritonavir for 24 hours. BACE1 was immunoprecipitated, as in $\mathbf{A}$, and visualized via autoradiography. Immature BACE1 runs at approximately $60 \mathrm{kDa}$, whereas mature, fully glycosylated BACE1 runs at approximately $70 \mathrm{kDa} .{ }^{38}$ Representative autoradiogram shown. C: The levels of ${ }^{35} \mathrm{~S}$-methionine/cysteine-labeled BACE1 were quantified and the percentage changes, relative to 0 hour time point, are plotted. No significant differences in BACE1 half-life were observed between control and ritonavir-treated neurons $(P>0.05$, linear regression analysis). All values represent means \pm SEM (C). $n=3$ (B and C). M, molecular weight; $\mathrm{mAb}$, monoclonal antibody; $\mathrm{ms}$, mouse; rb, rabbit; WC, whole cell.

depletion of ER $\mathrm{Ca}^{+},{ }^{2,17,71-73}$ and pharmacological inhibition of proteasome activity can activate PERK. ${ }^{79}$ Further studies will be necessary to determine whether PIs inhibit proteasome function in neurons, and if it precedes eIF $2 \alpha$ phosphorylation, and whether rescue of proteasome function abrogates these changes as well as potential downstream effects, including translational up-regulation of ATF4 and BACE1.

Our findings confirm a report by Vassar and colleagues, ${ }^{36}$ who showed chronic activation of UPR in neurons linked to $5^{\prime}$ UTR-dependent translational BACE1 up-regulation.
AZT, saquinavir, and ritonavir increased BACE1 expression in both rodent and human neurons after 16 hours, in parallel to increased nuclear ATF4. This increase in BACE1 was at least partially mediated by PERK; however, potential contribution of other eIF $2 \alpha$ kinases could be ruled out. Interestingly, PERK excision decreased p-eIF $2 \alpha$ and BACE1 levels, albeit had no effect on BiP or APP, indicating divergent mechanisms at play in ARV-treated neurons. Although $\mathrm{BiP}$ is transcriptionally regulated during ER stress, the mechanism of APP up-regulation remains unclear and may be unrelated to UPR activation.

More important, neither presenilin-1 C-terminal fragment, the $\gamma$-secretase subunit, nor ADAM metalloproteinase domain 10 showed any changes in expression after ARV treatment. Notably, mature $\gamma$-secretase is tightly regulated at multiple levels; thus, further studies will be necessary to conclusively determine whether ARVs alter the frequency and/or efficiency of $\gamma$-secretase cleavage via regulation of other essential subunits or cellular modulators of $\gamma$ secretase, including the $\gamma$-secretase activating protein. However, our results strongly suggest ARV-mediated specific BACE1 up-regulation is because of its unique mRNA structure. Unlike presenilin-1 and ADAM10, BACE1 mRNA contains three upstream open reading frames in its long, GC-rich, 5' UTR that suppress translation under normal cellular conditions ${ }^{36}$ and allow for more efficient BACE1 mRNA translation because of scan-through p-eIF2 $\alpha$ to bypass inhibitory upstream open reading frames; this is an evolutionarily conserved mechanism among many species to control translation of stress-related genes. ${ }^{69}$ However, it remains unclear what protective, if any, role BACE1 might have in neurons undergoing UPR.

One potentially detrimental consequence of elevated BACE1 expression is increased APP processing to generate $\mathrm{A} \beta$ peptides. Giunta et $\mathrm{al}^{80}$ was the first to show ARV-mediated A $\beta$ production in Swedish mutant APPoverexpressing $\mathrm{N} 2 \mathrm{a}$ cells. Our findings of ritonavirmediated $\mathrm{A} \beta_{42}$ increases in human APP-expressing $\mathrm{CHO}$ cells did not extend to $A \beta_{40}$ production, despite the detected $A R V$-mediated $A \beta_{40}$ increases in rat neuroglial culture media. This divergence may result from potential differences in APP processing in $\mathrm{CHO}$ cells versus neurons, as selective $\mathrm{A} \beta_{40}$ degradation was shown in these cells. Alternatively, APP overexpression may precipitate ER stress and UPR. Nonetheless, PI-induced induction of BACE1 accompanies increased BACE1 activity, which may alter APP processing in PI-exposed neurons.

In a previous study, Lan et $\mathrm{al}^{81}$ showed PIs, including ritonavir and saquinavir, modestly inhibited $\mathrm{A} \beta$ degradation in human macrophages, and decreased $\mathrm{A} \beta_{40}$ and BACE1 in human cortical neurons, whereas oral dosing with other PIs, nelfinavir or lopinavir/ritonavir, did not affect $A \beta$ accumulation in APP/severe combined immunodeficiency mice. Although these results appear to contradict our findings, several caveats must be considered. In that study, Transgenic Centre for Research in Neurodegenerative Diseases 8 


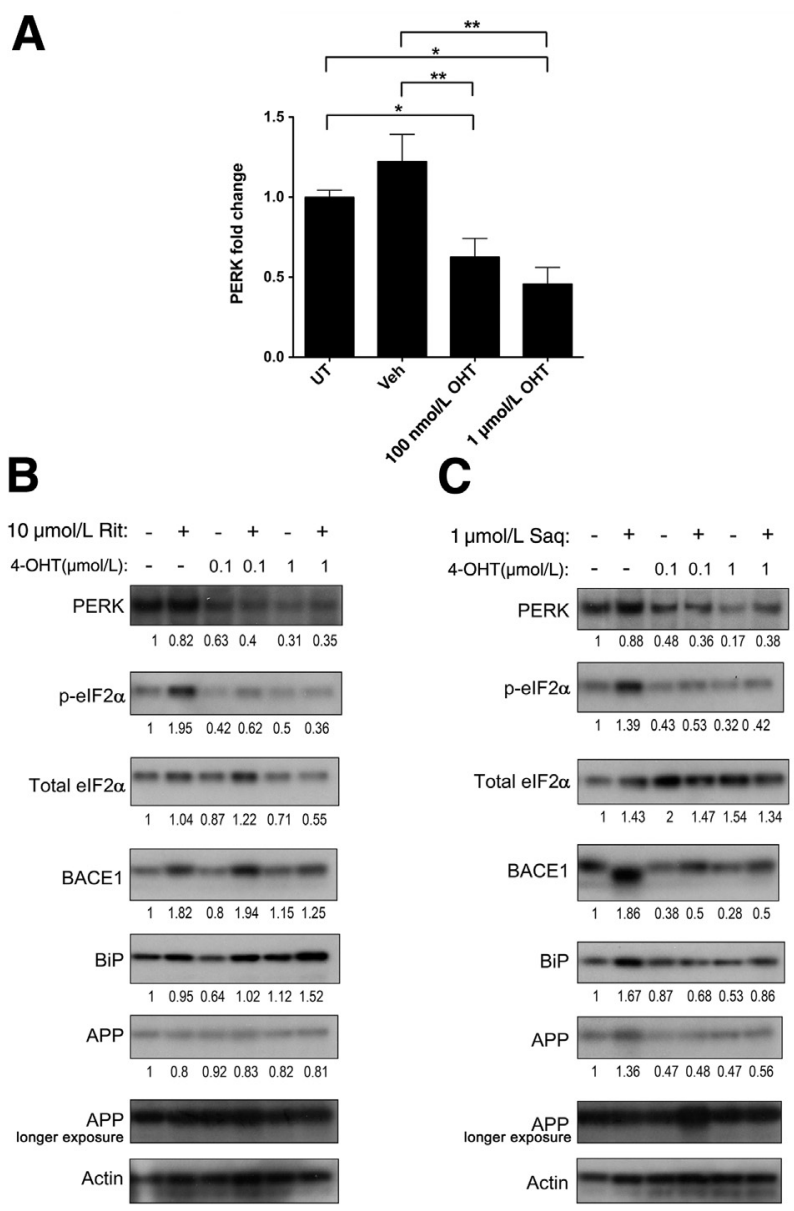

Figure 8 HIV protease inhibitor-mediated BACE1 up-regulation is PERK dependent. A-C: Floxed PERK mouse cortical neuroglial cultures were generated by isolating neurons from brains of tamoxifen-inducible cre recombinase conditional PERK knockout mice at embryonic day 16.5 to 17.5, and treatment with 0.1 or $1 \mu \mathrm{mol} / \mathrm{L}$ 4-hydroxtamoxifen (4-OHT) at $10 \mathrm{DIV}$ to excise PERK. At DIV 14, neuroglial cultures were used for experiments (estimated PERK half-life is 13 hours). A: Efficiency of PERK excision was estimated to be approximately $50 \%$ to $60 \%$ via densitometric analysis. Wildtype and PERK-excised neuroglial cultures were treated with $10 \mu \mathrm{mol} / \mathrm{L}$ ritonavir (Rit; B) or $1 \mu \mathrm{mol} / \mathrm{L}$ saquinavir (Saq; C) for 16 hours and lysates were immunoblotted. Representative images are shown. Fold changes are indicated below the blots, after normalization to actin. Compared to wildtype cultures, ARV-treated and PERK-excised neuroglial cultures showed reduced $\mathrm{p}$-eIF2 $\alpha$ and BACE1 expression. All values represent means \pm SEM (A). $n=4$ (A-C). ${ }^{*} P<0.05,{ }^{* *} P<0.01$ (one-way analysis of variance, Newman-Keuls post hoc). UT, untreated; Veh, vehicle.

(CRND8) mice develop plaque deposition at approximately 9 weeks of age, yet the APP severe combined immunodeficiency mice (BALB/cBy-Prkdc $c^{\text {scid }}$ crossed with CRND8) displayed no overt amyloid pathology at 12 weeks of age. Thus, inclusion of age-matched, CRND8 controls was necessary to ensure pathology in the APP severe combined immunodeficiency mice occurred in a similar, timedependent manner. Second, concentrations of PIs tested in human fetal neurons were 2.5- to 5-fold greater than the highest concentrations of PIs tested in our experiments, and ARV concentrations tested on purified BACE1 protein in vitro were up to 30 -fold greater than those used in our studies. Finally, we found that PIs had the greatest effect on $\mathrm{A} \beta_{42}$ production, whereas this was not tested by Lan et al. ${ }^{81}$ Notably, we found that ARVs at levels similar to those used by Lan et $\mathrm{al}^{80}$ were highly neurotoxic, even at time points earlier than 16 hours. Thus, further investigation is needed to resolve these findings.

Unlike $\alpha$ - or $\gamma$-secretases, BACE1 is translationally repressed under basal conditions but is selectively up-regulated during ER and oxidative stress; thus, we hypothesized a protective role for BACE1 in cellular stress adaptation and/or survival. In fact, BACE1-mediated $A \beta$ was protective against neuronal hyperactivity/excitotoxicity in vitro. ${ }^{82}$ However, our findings suggest that BACE1 may contribute to neuronal damage during ER stress over 48 hours, and raise questions regarding BACE1's physiological functions in neurons, which remain largely elusive. BACE1 has been implicated in myelination via cleavage of neuregulin-1 and in maintenance of synaptic functioning. ${ }^{38,83}$ BACE1 is also up-regulated in neurons in response to a host of inflammatory mediators, including interferon- $\gamma$, tumor necrosis factor- $\alpha$, and $A \beta$, and contains transcription factor binding sites for specificity protein 1 (Sp1), cAMP reponse element binding protein (CREB), and NF- $\kappa \mathrm{B}$, among others. These aspects of BACE1 need to be further investigated in future in vivo studies.

Based on our findings and previous reports, neuronal BACE1 up-regulation may be deleterious to cell survival during stress conditions. However, the cellular context of the specific stressor may be the critical determinant. As shown by Baleriola et $\mathrm{al}^{84} \mathrm{~A} \beta_{42}$ can induce p-eIF2 $\alpha$ accumulation and local translation of a subset of mRNAs, including ATF4, when applied to distal rat hippocampal neuronal axons. ATF4, typically considered neuroprotective in cellular adaption to ER stress, was shown to propagate a neurodegenerative signaling cascade in $A \beta_{42}$-treated neurons, leading to cell death. Thus, stress-induced genes, such as ATF4 and BACE1, that are translationally up-regulated in response to elevated p-eIF $2 \alpha$ detected in HAND and $\mathrm{AD} \mathrm{CNS}^{34,84,85}$ may be playing dual roles in neuronal viability, depending on stressor chronicity and localization. In addition, viral infection and inflammation are well-known UPR inducers. ${ }^{30,86}$ Furthermore, BACE1 expression is largely limited to neurons, whereas p-eIF2 $\alpha$ is ubiquitous; changes in p-eIF $2 \alpha$ might be masked in the cellular extracts containing all cell types. Overall, these factors may account for our in vivo findings showing p-eIF2 $\alpha$ elevation in $\mathrm{SIV}^{+} /$ placebo macaques, but not in ART-treated animals. These caveats should be examined in careful time-course experiments. Although our data suggest PI-mediated BACE1 up-regulation with concomitant functional activation, the implications of increased $A \beta$, an intriguing question beyond the scope of the current study, will be investigated in future studies.

Previous studies investigating amyloid pathology in brain specimens from ARV-medicated $\mathrm{HIV}^{+}$subjects have 
yielded conflicting results. Green et $\mathrm{al}^{5}$ were the first to show increased APP accumulation, primarily intraneuronal, and amyloid-associated pathology in ARV-treated, $\mathrm{HIV}^{+}$ individuals compared to $\mathrm{ARV}$-naïve, $\mathrm{HIV}^{+}$patients; these findings were confirmed by $\mathrm{Xu}$ and Ikezu, ${ }^{11}$ who observed intraneuronal $A \beta$ immunoreactivity and $A \beta$ plaques in ARV-treated, HIV encephalitic brains but only intraneuronal $A \beta$ in ARV-untreated, HAD brains, with no evidence of extracellular deposition. One major caveat in these studies is the pathological effects associated with variables such as comorbidities, drug abuse, and potential ARVmediated adverse effects. Thus, our studies in pigtailed macaque and rodent models of chronic ARV drug exposure were designed to tease out these confounders. In addition to increased hippocampal synaptodendritic damage we previously observed in ARV-treated $\mathrm{SIV}^{+}$macaques, we herein report elevated neuronal APP and BACE1 in the same cohort. Elevated APP has been previously reported to be associated with increased neuronal injury ${ }^{58}$; however, numerous reports indicate that this might be a neuroprotective response. ${ }^{87,88}$ In addition, roles for APP in synaptogenesis suggest that elevated APP may be an attempt at neuronal repair. Thus, our observation that altered APP levels among our treatment groups may be difficult to interpret. In addition, several caveats must be considered. First, the time to euthanasia was different between $\mathrm{SIV}^{+}$/ placebo and $\mathrm{SIV}^{+} / \mathrm{ART}$ groups, as these cohorts were originally designed to address a distinct question regarding use of ARVs. Second, SIV $^{+} /$ART macaques harbored persistent CNS viral DNA, although it was not clear if it was replication competent. ${ }^{43}$ Finally, this retrospective study did not include an $\mathrm{SIV}^{-} / \mathrm{ART}$ control group to more effectively account for ARV effects in the absence of virus. Future studies with $\mathrm{SIV}^{-} / \mathrm{ART}$ animals will be invaluable for isolating viral contribution to CNS damage from that of ARVs. More important, ARV concentrations in that model closely reflect dose ranges measured in human plasma and cerebrospinal fluid. ${ }^{43}$

Similar to our observations in $\mathrm{SIV}^{+} / \mathrm{ART}$ macaques, adult mice in our rodent model of chronic ARV exposure displayed increased hippocampal BACE1 expression, indicating virus-independent, ARV-mediated CNS BACE1 up-regulation. However, unlike ART-treated macaques, ARV-treated mice had increased p-eIF $2 \alpha$ and BiP expression, likely attributable to the use of different ARVs or species-specific differences in ARV effects in the hippocampus. These results build on our previous studies showing decreased MAP2 and synaptophysin in ARVtreated rat hippocampus, ${ }^{23}$ and taken together with our macaque data, suggest that ARVs, independent from potential viral effects, induce neuronal damage and UPR activation in the CNS and may contribute to the neurodegenerative processes associated with HAND.

Although CNS effects of ARVs are still poorly understood, clinical studies have begun to evaluate the effect of ARV regimens with high CNS penetration on $\mathrm{HIV}^{+}$ patients. Although numerous studies have shown ARVs' benefit in improving cognition, others have found a significant association between ARV regimens with high CNS penetration effectiveness scores and worse neurocognitive performance. ${ }^{3,53-55,89-96}$ Inherent and significant confounders in these studies are the variation in blood-brain barrier permeability among different ARVs, CNS viral load persistence, and the resulting difficulty in distinguishing neurotoxicity of HIV from that of ARVs. ARV drugs vary in their physicochemical properties, particularly regarding their blood-brain barrier permeability; however, extensive evidence demonstrates increased CNS entry of small molecules and serum proteins after HIV-mediated disruption of blood-brain barrier endothelial cells and tight junctions. ${ }^{97-100}$ Thus, higher-than-anticipated concentrations of ARV drugs may be occurring in $\mathrm{HIV}^{+}$patients with a compromised blood-brain barrier. Notably, pharmacokinetic analysis of ARVs in guinea pigs revealed significantly higher uptake of $\left[{ }^{3} \mathrm{H}\right]$-ritonavir into brain parenchyma compared to cerebrospinal fluid, suggesting that clinical estimates of CNS penetrance for PIs may be lower than actual CNS drug concentrations. ${ }^{63}$ In addition to uncertainties in ARV CNS penetration with currently prescribed regimens, efforts to enhance ARV delivery to the CNS via nanotherapeutics necessitate a careful examination of their potential neurotoxic effects.

Although ARV concentrations used herein were significantly higher than peak CNS levels measured in patients, their effects on neuroglial cultures are likely to occur over long-term exposures in vivo. We sought to model their chronic, low-dose effects in a more acute time frame with higher doses. Our results indicated that PIs, at nanomolar concentrations, robustly activated the UPR in primary cortical neurons, leading to PERK-dependent increases in p-eIF $2 \alpha$ and BACE1 translational up-regulation. ARVs, either alone or in combination, also increased $A \beta$ production in multiple cell types, which was dose-dependently blocked by a cell-permeable BACE1 inhibitor. Taken together with our previous reports of elevated BiP, p-eIF2 $\alpha$, and ATF6 in HAND tissue, these data strongly suggest a role for UPR in CNS HIV pathogenesis. These results bear striking similarities to observations made in $\mathrm{AD}$, Parkinson disease, amyotrophic lateral sclerosis, and prion diseases in which UPR markers, including phospho-PERK, are elevated in multiple brain regions. Although transient eIF $2 \alpha$ phosphorylation is protective during ER stress, sustained global protein synthesis suppression in the CNS may ultimately lead to impaired long-term potentiation and synaptic failure. However, promising therapeutics targeted at the UPR have already been reported. Several studies showed genetic and pharmacological suppression of PERK activity decreased p-eIF2 $\alpha$ expression, improved synaptic plasticity, and rescued memory deficits in an AD mouse model, and alleviated prion-mediated pathology and cognitive deficits in prion protein-inoculated mice. ${ }^{86,101}$ In addition, BACE1 inhibitors, which are currently being aggressively pursued in 
clinical trials, may have therapeutic benefits in patients experiencing HAND. $^{83}$ Future investigations will be necessary to determine the role of BACE1 in UPR. We also propose to investigate ARVs' potential effects on BACE1 redistribution to the trans-Golgi network and early endosomal compartments as a mechanism of increased APP processing, similar to what was shown by Tan et al. ${ }^{75}$ Such approaches, in a precision medicine setting, will aid the clinicians in determining the most efficient ART regimens with minimal adverse effects that can be reinforced with the most appropriate adjunctive therapeutic approaches, such as BACE1 inhibitors.

\section{Acknowledgments}

We thank Margaret Maronski for her help in the preparation of primary rat cortical cultures; and Ron Wek (Indiana University) for providing ATF4 antibody.

P.J.G., C.A.E., L.A.B., M.A.E., B.B.G., N.S.K., B.K.J., N.J.H., A.J.G., R.C.P., D.L.K., J.A.D., J.L.M., and K.L.J.-S. conceived and designed the experiments; P.J.G., C.A.E., A.C.Y., L.A.B., M.A.E., N.S.K., G.V.W., and B.K.J. performed the experiments; P.J.G., C.A.E., A.C.Y., N.S.K., B.K.J., A.J.G., D.L.K., and K.L.J.-S. analyzed the data; L.A.B., B.B.G., Y.G., N.J.H., M.C.Z., J.E.C., R.V., R.C.P., J.A.D., and J.L.M. contributed reagents/materials/analysis tools; and P.J.G., C.A.E., M.A.E., B.B.G., B.K.J., D.L.K., J.L.M., and K.L.J.-S. contributed to the writing of the manuscript.

\section{References}

1. Heaton RK, Franklin DR, Ellis RJ, McCutchan JA, Letendre SL, Leblanc S, Corkran SH, Duarte NA, Clifford DB, Woods SP, Collier AC, Marra CM, Morgello S, Mindt MR, Taylor MJ, Marcotte TD, Atkinson JH, Wolfson T, Gelman BB, McArthur JC, Simpson DM, Abramson I, Gamst A, Fennema-Notestine C, Jernigan TL, Wong J, Grant I: HIV-associated neurocognitive disorders before and during the era of combination antiretroviral therapy: differences in rates, nature, and predictors. J Neurovirol 2010, 17:3-16

2. McArthur JC, Steiner J, Sacktor N, Nath A: Human immunodeficiency virus-associated neurocognitive disorders mind the gap. Ann Neurol 2010, 67:699-714

3. Robertson KR, Smurzynski M, Parsons TD, Wu K, Bosch RJ, Wu J, McArthur JC, Collier AC, Evans SR, Ellis RJ: The prevalence and incidence of neurocognitive impairment in the HAART era. AIDS 2007, 21:1915-1921

4. Bandaru VV, McArthur JC, Sacktor N, Cutler RG, Knapp EL, Mattson MP, Haughey NJ: Associative and predictive biomarkers of dementia in HIV-1-infected patients. Neurology 2007, 68:1481-1487

5. Green DA, Masliah E, Vinters HV, Beizai P, Moore DJ, Achim CL: Brain deposition of beta-amyloid is a common pathologic feature in HIV positive patients. AIDS 2005, 19:407-411

6. Anthony IC, Ramage SN, Carnie FW, Simmonds P, Bell JE: Accelerated Tau deposition in the brains of individuals infected with human immunodeficiency virus-1 before and after the advent of highly active anti-retroviral therapy. Acta Neuropathol 2006, 111: 529-538
7. Achim CL, Adame A, Dumaop W, Everall IP, Masliah E: Increased accumulation of intraneuronal amyloid beta in HIV-infected patients. J Neuroimmune Pharmacol 2009, 4:190-199

8. Brew BJ, Pemberton L, Blennow K, Wallin A, Hagberg L: CSF amyloid beta42 and tau levels correlate with AIDS dementia complex. Neurology 2005, 65:1490-1492

9. Vehmas A, Lieu J, Pardo CA, McArthur JC, Gartner S: Amyloid precursor protein expression in circulating monocytes and brain macrophages from patients with HIV-associated cognitive impairment. J Neuroimmunol 2004, 157:99-110

10. Esiri MM, Biddolph SC, Morris CS: Prevalence of Alzheimer plaques in AIDS. J Neurol Neurosurg Psychiatry 1998, 65:29-33

11. Xu J, Ikezu T: The comorbidity of HIV-associated neurocognitive disorders and Alzheimer's disease: a foreseeable medical challenge in post-HAART era. J Neuroimmune Pharmacol 2009, 4:200-212

12. Sosnik A, Chiappetta DA, Carcaboso AM: Drug delivery systems in HIV pharmacotherapy: what has been done and the challenges standing ahead. J Control Release 2009, 138:2-15

13. De Clercq E: New anti-HIV agents and targets. Med Res Rev 2002, 22:531-565

14. Moyle G: Mechanisms of HIV and nucleoside reverse transcriptase inhibitor injury to mitochondria. Antivir Ther 2005, 10 Suppl 2: M47-M52

15. Chen CH, Vazquez-Padua M, Cheng YC: Effect of anti-human immunodeficiency virus nucleoside analogs on mitochondrial DNA and its implication for delayed toxicity. Mol Pharmacol 1991, 39: 625-628

16. Dufer M, Neye Y, Krippeit-Drews P, Drews G: Direct interference of HIV protease inhibitors with pancreatic beta-cell function. Naunyn Schmiedebergs Arch Pharmacol 2004, 369:583-590

17. Zhou H, Gurley EC, Jarujaron S, Ding H, Fang Y, Xu Z, Pandak WM Jr, Hylemon PB: HIV protease inhibitors activate the unfolded protein response and disrupt lipid metabolism in primary hepatocytes. Am J Physiol Gastrointest Liver Physiol 2006, 291: G1071-G1080

18. Schutt M, Zhou J, Meier M, Klein HH: Long-term effects of HIV-1 protease inhibitors on insulin secretion and insulin signaling in INS-1 beta cells. J Endocrinol 2004, 183:445-454

19. Liang JS, Distler O, Cooper DA, Jamil H, Deckelbaum RJ, Ginsberg HN, Sturley SL: HIV protease inhibitors protect apolipoprotein $\mathrm{B}$ from degradation by the proteasome: a potential mechanism for protease inhibitor-induced hyperlipidemia. Nat Med 2001, 7 : $1327-1331$

20. Schubert M, Gautam D, Surjo D, Ueki K, Baudler S, Schubert D, Kondo T, Alber J, Galldiks N, Kustermann E, Arndt S, Jacobs AH, Krone W, Kahn CR, Bruning JC: Role for neuronal insulin resistance in neurodegenerative diseases. Proc Natl Acad Sci U S A 2004, 101: $3100-3105$

21. Steen E, Terry BM, Rivera EJ, Cannon JL, Neely TR, Tavares R, $\mathrm{Xu} \mathrm{XJ}$, Wands JR, de la Monte SM: Impaired insulin and insulinlike growth factor expression and signaling mechanisms in Alzheimer's disease: is this type 3 diabetes? J Alzheimers Dis 2005, 7:63-80

22. Banerjee A, Abdelmegeed MA, Jang S, Song BJ: Zidovudine (AZT) and hepatic lipid accumulation: implication of inflammation, oxidative and endoplasmic reticulum stress mediators. PLoS One 2013, 8: e76850

23. Akay C, Cooper M, Odeleye A, Jensen BK, White MG, Vassoler F, Gannon PJ, Mankowski J, Dorsey JL, Buch AM, Cross SA Cook DR, Pena MM, Andersen ES, Christofidou-Solomidou M, Lindl KA, Zink MC, Clements J, Pierce RC, Kolson DL, JordanSciutto KL: Antiretroviral drugs induce oxidative stress and neuronal damage in the central nervous system. J Neurovirol 2014, 20:39-53

24. Robertson K, Liner J, Meeker RB: Antiretroviral neurotoxicity. J Neurovirol 2012, 18:388-399

25. Everall IP, Hansen LA, Masliah E: The shifting patterns of HIV encephalitis neuropathology. Neurotox Res 2005, 8:51-61 
26. Lindl KA, Akay C, Wang Y, White MG, Jordan-Sciutto KL: Expression of the endoplasmic reticulum stress response marker, BiP, in the central nervous system of HIV-positive individuals. Neuropathol Appl Neurobiol 2007, 33:658-669

27. Markowitz AJ, White MG, Kolson DL, Jordan-Sciutto KL: Cellular interplay between neurons and glia: toward a comprehensive mechanism for excitotoxic neuronal loss in neurodegeneration. Cell Sci 2007, 4:111-146

28. Rao RV, Bredesen DE: Misfolded proteins, endoplasmic reticulum stress and neurodegeneration. Curr Opin Cell Biol 2004, 16: $653-662$

29. Bertolotti A, Zhang Y, Hendershot LM, Harding HP, Ron D: Dynamic interaction of BiP and ER stress transducers in the unfolded-protein response. Nat Cell Biol 2000, 2:326-332

30. Salminen A, Kauppinen A, Suuronen T, Kaarniranta K, Ojala J: ER stress in Alzheimer's disease: a novel neuronal trigger for inflammation and Alzheimer's pathology. J Neuroinflammation 2009, 6:41

31. Lindl KA, Marks DR, Kolson DL, Jordan-Sciutto KL: HIV-associated neurocognitive disorder: pathogenesis and therapeutic opportunities. J Neuroimmune Pharmacol 2010, 5:294-309

32. Takahashi K, Niidome T, Akaike A, Kihara T, Sugimoto H: Amyloid precursor protein promotes endoplasmic reticulum stress-induced cell death via C/EBP homologous protein-mediated pathway. J Neurochem 2009, 109:1324-1337

33. Kudo T, Okumura M, Imaizumi K, Araki W, Morihara T, Tanimukai H, Kamagata E, Tabuchi N, Kimura R, Kanayama D, Fukumori A, Tagami S, Okochi M, Kubo M, Tanii H, Tohyama M, Tabira T, Takeda M: Altered localization of amyloid precursor protein under endoplasmic reticulum stress. Biochem Biophys Res Commun 2006, 344:525-530

34. Hoozemans JJ, van Haastert ES, Nijholt DA, Rozemuller AJ, Eikelenboom P, Scheper W: The unfolded protein response is activated in pretangle neurons in Alzheimer's disease hippocampus. Am J Pathol 2009, 174:1241-1251

35. Velliquette RA, O'Connor T, Vassar R: Energy inhibition elevates beta-secretase levels and activity and is potentially amyloidogenic in APP transgenic mice: possible early events in Alzheimer's disease pathogenesis. J Neurosci 2005, 25:10874-10883

36. O'Connor T, Sadleir KR, Maus E, Velliquette RA, Zhao J, Cole SL, Eimer WA, Hitt B, Bembinster LA, Lammich S, Lichtenthaler SF, Hebert SS, De Strooper B, Haass C, Bennett DA, Vassar R: Phosphorylation of the translation initiation factor eIF2 alpha increases BACE1 levels and promotes amyloidogenesis. Neuron 2008, 60: 988-1009

37. Finnie JW, Manavis J, Blumbergs PC, Kuchel TR: Axonal and neuronal amyloid precursor protein immunoreactivity in the brains of guinea pigs given tunicamycin. Vet Pathol 2000, 37:677-680

38. Vassar R: BACE1: the beta-secretase enzyme in Alzheimer's disease. J Mol Neurosci 2004, 23:105-113

39. Cheng X, He P, Lee T, Yao H, Li R, Shen Y: High activities of BACE1 in brains with mild cognitive impairment. Am J Pathol 2014, 184:141-147

40. Committee for the Update of the Guide for the Care and Use of Laboratory Animals; National Research Council: Guide for the Care and Use of Laboratory Animals. ed 8. Washington, DC, National Academies Press, 2011

41. Zink MC, Suryanarayana K, Mankowski JL, Shen A, Piatak M Jr, Spelman JP, Carter DL, Adams RJ, Lifson JD, Clements JE: High viral load in the cerebrospinal fluid and brain correlates with severity of simian immunodeficiency virus encephalitis. J Virol 1999, 73: 10480-10488

42. Hazuda DJ, Young SD, Guare JP, Anthony NJ, Gomez RP, Wai JS, Vacca JP, Handt L, Motzel SL, Klein HJ, Dornadula G, Danovich RM, Witmer MV, Wilson KA, Tussey L, Schleif WA, Gabryelski LS, Jin L, Miller MD, Casimiro DR, Emini EA, Shiver JW: Integrase inhibitors and cellular immunity suppress retroviral replication in rhesus macaques. Science 2004, 305:528-532
43. Zink MC, Brice AK, Kelly KM, Queen SE, Gama L, Li M, Adams RJ, Bartizal C, Varrone J, Rabi SA, Graham DR, Tarwater PM, Mankowski JL, Clements JE: Simian immunodeficiency virus-infected macaques treated with highly active antiretroviral therapy have reduced central nervous system viral replication and inflammation but persistence of viral DNA. J Infect Dis 2010, 202:161-170

44. Tsai CC, Follis KE, Beck TW, Sabo A, Bischofberger N, Dailey PJ: Effects of (R)-9-(2-phosphonylmethoxypropyl)adenine monotherapy on chronic SIV infection in macaques. AIDS Res Hum Retroviruses 1997, 13:707-712

45. Briand LA, Lee FS, Blendy JA, Pierce RC: Enhanced extinction of cocaine seeking in brain-derived neurotrophic factor Val66Met knock-in mice. Eur J Neurosci 2012, 35:932-939

46. Pistell PJ, Gupta S, Knight AG, Domingue M, Uranga RM, Ingram DK, Kheterpal I, Ruiz C, Keller JN, Bruce-Keller AJ: Metabolic and neurologic consequences of chronic lopinavir/ritonavir administration to C57BL/6 mice. Antiviral Res 2010, 88: 334-342

47. du Plooy M, Viljoen M, Rheeders M: Evidence for time-dependent interactions between ritonavir and lopinavir/ritonavir plasma levels following P-glycoprotein inhibition in Sprague-Dawley rats. Biol Pharm Bull 2011, 34:66-70

48. Kageyama M, Namiki H, Fukushima H, Terasaka S, Togawa T, Tanaka A, Ito Y, Shibata N, Takada K: Effect of chronic administration of ritonavir on function of cytochrome P450 3A and P-glycoprotein in rats. Biol Pharm Bull 2005, 28:130-137

49. Wilcox KS, Buchhalter J, Dichter MA: Properties of inhibitory and excitatory synapses between hippocampal-neurons in very-lowdensity cultures. Synapse 1994, 18:128-151

50. Akay C, Lindl KA, Wang Y, White MG, Isaacman-Beck J, Kolson DL, Jordan-Sciutto KL: Site-specific hyperphosphorylation of $\mathrm{pRb}$ in HIV-induced neurotoxicity. Mol Cell Neurosci 2011, 47: $154-165$

51. Darbinian N, Khalili K, Amini S: Neuroprotective activity of pDING in response to HIV-1 tat. J Cell Physiol 2014, 229:153-161

52. Trinh MA, Kaphzan H, Wek RC, Pierre P, Cavener DR, Klann E: Brain-specific disruption of the eIF2 alpha kinase PERK decreases ATF4 expression and impairs behavioral flexibility. Cell Rep 2012, 1: 676-688

53. Marra CM, Zhao Y, Clifford DB, Letendre S, Evans S, Henry K, Ellis RJ, Rodriguez B, Coombs RW, Schifitto G, McArthur JC, Robertson K: Impact of combination antiretroviral therapy on cerebrospinal fluid HIV RNA and neurocognitive performance. AIDS 2009, 23:1359-1366

54. Kahouadji Y, Dumurgier J, Sellier P, Lapalus P, Delcey V, Bergmann JF, Hugon J, Paquet C: Cognitive function after several years of antiretroviral therapy with stable central nervous system penetration score. HIV Med 2013, 14:311-315

55. Joska JA, Gouse H, Paul RH, Stein DJ, Flisher AJ: Does highly active antiretroviral therapy improve neurocognitive function? a systematic review. J Neurovirol 2010, 16:101-114

56. Mankowski JL, Queen SE, Tarwater PM, Fox KJ, Perry VH: Accumulation of beta-amyloid precursor protein in axons correlates with CNS expression of SIV gp41. J Neuropathol Exp Neurol 2002, 61: $85-90$

57. Schirmer L, Antel JP, Bruck W, Stadelmann C: Axonal loss and neurofilament phosphorylation changes accompany lesion development and clinical progression in multiple sclerosis. Brain Pathol 2011, 21:428-440

58. Uryu $\mathrm{K}$, Chen $\mathrm{XH}$, Martinez $\mathrm{D}$, Browne $\mathrm{KD}$, Johnson VE, Graham DI, Lee VM, Trojanowski JQ, Smith DH: Multiple proteins implicated in neurodegenerative diseases accumulate in axons after brain trauma in humans. Exp Neurol 2007, 208: $185-192$

59. Nebuloni M, Pellegrinelli A, Ferri A, Bonetto S, Boldorini R, Vago L, Grassi MP, Costanzi G: Beta amyloid precursor protein and 
patterns of HIV p24 immunohistochemistry in different brain areas of AIDS patients. AIDS 2001, 15:571-575

60. An SF, Giometto B, Groves M, Miller RF, Beckett AA, Gray F, Tavolato B, Scaravilli F: Axonal damage revealed by accumulation of beta-APP in HIV-positive individuals without AIDS. J Neuropathol Exp Neurol 1997, 56:1262-1268

61. Busidan Y, Dow-Edwards DL: Neurobehavioral effects of perinatal AZT exposure in Sprague-Dawley weaning rats. Pharmacol Biochem Behav 1999, 64:479-485

62. Werth JL, Zhou B, Nutter LM, Thayer SA: 2',3'-Dideoxycytidine alters calcium buffering in cultured dorsal root ganglion neurons. Mol Pharmacol 1994, 45:1119-1124

63. Anthonypillai C, Sanderson RN, Gibbs JE, Thomas SA: The distribution of the HIV protease inhibitor, ritonavir, to the brain, cerebrospinal fluid, and choroid plexuses of the guinea pig. J Pharmacol Exp Ther 2004, 308:912-920

64. Wynn HE, Brundage RC, Fletcher CV: Clinical implications of CNS penetration of antiretroviral drugs. CNS Drugs 2002, 16:595-609

65. Mouton-Liger F, Paquet C, Dumurgier J, Bouras C, Pradier L, Gray F, Hugon J: Oxidative stress increases BACE1 protein levels through activation of the PKR-eIF2alpha pathway. Biochim Biophys Acta 2012, 1822:885-896

66. Vassar R, Bennett BD, Babu-Khan S, Kahn S, Mendiaz EA, Denis P, Teplow DB, Ross S, Amarante P, Loeloff R, Luo Y, Fisher S, Fuller J, Edenson S, Lile J, Jarosinski MA, Biere AL, Curran E, Burgess T, Louis JC, Collins F, Treanor J, Rogers G, Citron M: Betasecretase cleavage of Alzheimer's amyloid precursor protein by the transmembrane aspartic protease BACE. Science 1999, 286:735-741

67. Moussavi Nik SH, Wilson L, Newman M, Croft K, Mori TA, Musgrave I, Lardelli M: The BACE1-PSEN-AbetaPP regulatory axis has an ancient role in response to low oxygen/oxidative stress. J Alzheimers Dis 2012, 28:515-530

68. Ill-Raga G, Palomer E, Wozniak MA, Ramos-Fernandez E, BoschMorato M, Tajes M, Guix FX, Galan JJ, Clarimon J, Antunez C, Real LM, Boada M, Itzhaki RF, Fandos C, Munoz FJ: Activation of PKR causes amyloid beta-peptide accumulation via de-repression of BACE1 expression. PLoS One 2011, 6:e21456

69. Wek RC, Cavener DR: Translational control and the unfolded protein response. Antioxid Redox Signal 2007, 9:2357-2371

70. Lammich S, Schobel S, Zimmer AK, Lichtenthaler SF, Haass C: Expression of the Alzheimer protease BACE1 is suppressed via its 5'untranslated region. EMBO Rep 2004, 5:620-625

71. Andre P, Groettrup M, Klenerman P, de Giuli R, Booth BL Jr, Cerundolo V, Bonneville M, Jotereau F, Zinkernagel RM, Lotteau V: An inhibitor of HIV-1 protease modulates proteasome activity, antigen presentation, and T cell responses. Proc Natl Acad Sci U S A 1998, 95:13120-13124

72. Parker RA, Flint OP, Mulvey R, Elosua C, Wang F, Fenderson W, Wang S, Yang WP, Noor MA: Endoplasmic reticulum stress links dyslipidemia to inhibition of proteasome activity and glucose transport by HIV protease inhibitors. Mol Pharmacol 2005, 67:1909-1919

73. Piccinini M, Rinaudo MT, Chiapello N, Ricotti E, Baldovino S, Mostert M, Tovo PA: The human 26S proteasome is a target of antiretroviral agents. AIDS 2002, 16:693-700

74. Huse JT, Pijak DS, Leslie GJ, Lee VM, Doms RW: Maturation and endosomal targeting of beta-site amyloid precursor protein-cleaving enzyme: the Alzheimer's disease beta-secretase. J Biol Chem 2000, 275:33729-33737

75. Tan JL, Li QX, Ciccotosto GD, Crouch PJ, Culvenor JG, White AR, Evin G: Mild oxidative stress induces redistribution of BACE1 in non-apoptotic conditions and promotes the amyloidogenic processing of Alzheimer's disease amyloid precursor protein. PLoS One 2013, 8: e61246

76. Devi L, Ohno M: PERK mediates eIF2alpha phosphorylation responsible for BACE1 elevation, CREB dysfunction and neurodegeneration in a mouse model of Alzheimer's disease. Neurobiol Aging 2014, 35:2272-2281
77. Ohno M: Roles of eIF2alpha kinases in the pathogenesis of Alzheimer's disease. Front Mol Neurosci 2014, 7:22

78. Deeks SG: Immune dysfunction, inflammation, and accelerated aging in patients on antiretroviral therapy. Top HIV Med 2009, 17: $118-123$

79. Wu X, Sun L, Zha W, Studer E, Gurley E, Chen L, Wang X, Hylemon PB, Pandak WM, Sanyal AJ, Zhang L, Wang G, Chen J, Wang JY, Zhou H: HIV protease inhibitors induce endoplasmic reticulum stress and disrupt barrier integrity in intestinal epithelial cells. Gastroenterology 2010, 138:197

80. Giunta B, Ehrhart J, Obregon DF, Lam L, Le L, Jin J, Fernandez F, Tan J, Shytle RD: Antiretroviral medications disrupt microglial phagocytosis of beta-amyloid and increase its production by neurons: implications for HIV-associated neurocognitive disorders. Mol Brain 2011, 4:23

81. Lan X, Kiyota T, Hanamsagar R, Huang Y, Andrews S, Peng H, Zheng JC, Swindells S, Carlson GA, Ikezu T: The effect of HIV protease inhibitors on amyloid-beta peptide degradation and synthesis in human cells and Alzheimer's disease animal model. J Neuroimmune Pharmacol 2011, 7:412-423

82. Kamenetz F, Tomita T, Hsieh H, Seabrook G, Borchelt D, Iwatsubo T, Sisodia S, Malinow R: APP processing and synaptic function. Neuron 2003, 37:925-937

83. Vassar R, Kuhn PH, Haass C, Kennedy ME, Rajendran L, Wong PC, Lichtenthaler SF: Function, therapeutic potential and cell biology of BACE proteases: current status and future prospects. J Neurochem 2014, 130:4-28

84. Baleriola J, Walker CA, Jean YY, Crary JF, Troy CM, Nagy PL, Hengst U: Axonally synthesized ATF4 transmits a neurodegenerative signal across brain regions. Cell 2014, 158:1159-1172

85. Akay C, Lindl KA, Shyam N, Nabet B, Goenaga-Vazquez Y, Ruzbarsky J, Wang Y, Kolson DL, Jordan-Sciutto KL: Activation status of integrated stress response pathways in neurones and astrocytes of HIV-associated neurocognitive disorders (HAND) cortex. Neuropathol Appl Neurobiol 2012, 38:175-200

86. Moreno JA, Halliday M, Molloy C, Radford H, Verity N, Axten JM, Ortori CA, Willis AE, Fischer PM, Barrett DA, Mallucci GR: Oral treatment targeting the unfolded protein response prevents neurodegeneration and clinical disease in prion-infected mice. Sci Transl Med 2013, 5:206ra138

87. Schubert D, Behl C: The expression of amyloid beta protein precursor protects nerve cells from beta-amyloid and glutamate toxicity and alters their interaction with the extracellular matrix. Brain Res 1993, $629: 275-282$

88. Dawson GR, Seabrook GR, Zheng H, Smith DW, Graham S, O’Dowd G, Bowery BJ, Boyce S, Trumbauer ME, Chen HY, Van der Ploeg LH, Sirinathsinghji DJ: Age-related cognitive deficits, impaired long-term potentiation and reduction in synaptic marker density in mice lacking the beta-amyloid precursor protein. Neuroscience 1999 , 90:1-13

89. Cysique LA, Maruff P, Brew BJ: Prevalence and pattern of neuropsychological impairment in human immunodeficiency virus-infected/acquired immunodeficiency syndrome (HIV/AIDS) patients across pre- and post-highly active antiretroviral therapy eras: a combined study of two cohorts. J Neurovirol 2004, 10 $350-357$

90. Smurzynski M, Wu K, Letendre S, Robertson K, Bosch RJ, Clifford DB, Evans S, Collier AC, Taylor M, Ellis R: Effects of central nervous system antiretroviral penetration on cognitive functioning in the ALLRT cohort. AIDS 2010, 25:357-365

91. Letendre SL, McCutchan JA, Childers ME, Woods SP, Lazzaretto D, Heaton RK, Grant I, Ellis RJ, Group H: Enhancing antiretroviral therapy for human immunodeficiency virus cognitive disorders. Ann Neurol 2004, 56:416-423

92. Letendre S, Marquie-Beck J, Capparelli E, Best B, Clifford D, Collier AC, Gelman BB, McArthur JC, McCutchan JA, Morgello S, Simpson D, Grant I, Ellis RJ: Validation of the CNS 
penetration-effectiveness rank for quantifying antiretroviral penetration into the central nervous system. Arch Neurol 2008, 65:65-70

93. Winston A, Duncombe C, Li PC, Gill JM, Kerr SJ, Puls R, Petoumenos K, Taylor-Robinson SD, Emery S, Cooper DA, Altair Study G: Does choice of combination antiretroviral therapy (cART) alter changes in cerebral function testing after 48 weeks in treatmentnaive, HIV-1-infected individuals commencing cART? a randomized, controlled study. Clin Infect Dis 2010, 50:920-929

94. Schweinsburg BC, Taylor MJ, Alhassoon OM, Gonzalez R, Brown GG, Ellis RJ, Letendre S, Videen JS, McCutchan JA, Patterson TL, Grant I: Brain mitochondrial injury in human immunodeficiency virus-seropositive $(\mathrm{HIV}+)$ individuals taking nucleoside reverse transcriptase inhibitors. J Neurovirol 2005, 11:356-364

95. Cardenas VA, Meyerhoff DJ, Studholme C, Kornak J, Rothlind J, Lampiris H, Neuhaus J, Grant RM, Chao LL, Truran D, Weiner MW: Evidence for ongoing brain injury in human immunodeficiency viruspositive patients treated with antiretroviral therapy. J Neurovirol 2009, 15:324-333

96. Tozzi V, Balestra P, Salvatori MF, Vlassi C, Liuzzi G, Giancola ML, Giulianelli M, Narciso P, Antinori A: Changes in cognition during antiretroviral therapy: comparison of 2 different ranking systems to measure antiretroviral drug efficacy on HIV-associated neurocognitive disorders. Jaids-J Acq Imm Def 2009, 52:56-63

97. Cysique LA, Brew BJ: Neuropsychological functioning and antiretroviral treatment in HIV/AIDS: a review. Neuropsychol Rev 2009, 19:169-185

98. Yilmaz A, Stahle L, Hagberg L, Svennerholm B, Fuchs D, Gisslen M: Cerebrospinal fluid and plasma HIV-1 RNA levels and lopinavir concentrations following lopinavir/ritonavir regimen. Scand J Infect Dis 2004, 36:823-828

99. Varatharajan L, Thomas SA: The transport of anti-HIV drugs across blood-CNS interfaces: summary of current knowledge and recommendations for further research. Antiviral Res 2009, 82:A99-A109

100. Wang H, Sun J, Goldstein H: Human immunodeficiency virus type 1 infection increases the in vivo capacity of peripheral monocytes to cross the blood-brain barrier into the brain and the in vivo sensitivity of the blood-brain barrier to disruption by lipopolysaccharide. J Virol 2008, 82:7591-7600

101. Ma T, Trinh MA, Wexler AJ, Bourbon C, Gatti E, Pierre P, Cavener DR, Klann E: Suppression of eIF2 alpha kinases alleviates Alzheimer's disease-related plasticity and memory deficits. Nat Neurosci 2013, 16:1299-1305 